Cite this: RSC Adv., 2014, 4, 12763

\title{
In vitro/In vivo assessment and mechanisms of toxicity of bioceramic materials and its wear particulates
}

\begin{abstract}
Greeshma Thrivikraman, $^{\text {ab }}$ Giridhar Madras $^{\mathrm{b}}$ and Bikramjit Basu*a
With the progress in modern technological research, novel biomaterials are being largely developed for various biomedical applications. Over the past two decades, most of the research focuses on the development of a new generation of bioceramics as substitutes for hard tissue replacement. In reference to their application in different anatomical locations of a patient, newly developed bioceramic materials can potentially induce a toxic/harmful effect to the host tissues. Therefore, prior to clinical testing, relevant biochemical screening assays are to be performed at the cellular and molecular level, to address the issues of biocompatibility and long term performance of the implants. Along with testing strategies in the bulk material toxicity, a detailed evaluation should also be conducted to determine the toxicity of the wear products of the potential bioceramics. This is important as the bioceramics are intended to be implanted in patients with longer life expectancy and notwithstanding, the material will eventually release finer (mostly nanosized) sized debris particles due to continuous wear at articulating surfaces in the hostile corrosive environment of the human body. The wear particulates generated from a biocompatible bioceramic may act in a different way, inducing early/late aseptic loosening at the implant site, resulting in osteolysis and inflammation. Hence, a study on the chronic effects of the wear particulates, in terms of local and systemic toxicity becomes the major criteria in the toxicity evaluation of implantable bioceramics. In this broad perspective, this article summarizes some of the currently used techniques and knowledge in assessing the in vitro and in vivo cytotoxicity and genotoxicity of bioceramic implant materials. It also addresses the need to conduct a broad evaluation before claiming the biocompatibility and clinical feasibility of any new biomaterial. This review also emphasizes some of the case studies based on the experimental designs that are currently followed and its importance in the context of clinical applications.
\end{abstract}

Received 19th August 2013 Accepted 6th January 2014

DOI: 10.1039/c3ra44483j

www.rsc.org/advances

\section{Introduction}

The field of biomaterial technology has rapidly progressed over the last few decades with the advent of advanced medical devices and implants developed from metals, ceramic and polymeric materials. ${ }^{1}$ Bioceramics are an important subset of biomaterials, employed in medical and orthopedic applications, mainly for the repair and replacement of diseased and damaged parts of the human skeleton, bone, teeth and joints. ${ }^{2,3}$ They are currently the major players in the orthopedic market, ${ }^{4}$ due to their high biocompatibility and osseointegration, and most importantly because of their similarity to the mineral component of bones (hydroxyapatite). ${ }^{3}$ Other advantages of bioceramics include low chemical reactivity, being almost totally inert and, therefore, non-toxicity. However, not all

${ }^{a}$ Laboratory for Biomaterials, Materials Research Centre, Indian Institute of Science, Bangalore 560012, India. E-mail: bikram@mrc.iisc.ernet.in

${ }^{b}$ Centre for Nano Science and Engineering, Indian Institute of Science, Bangalore 560012, India bioceramics implanted are chemically inert, and in fact, elicit a response at the tissue-implant interface. ${ }^{5}$ Modern ceramic technology has vast potential in formulating porous and moldable ceramics, making them an excellent scaffolding material for tissue growth. Based on the common response of tissues to implants, bioceramics are mainly classified into three groups; (1) bioinert ceramics, (2) bioactive ceramics and (3) bioresorbable ceramics. ${ }^{6}$ Alumina $\left(\mathrm{Al}_{2} \mathrm{O}_{3}\right)$ and zirconia $\left(\mathrm{ZrO}_{2}\right)$ fall under the category of bioinert materials, which are otherwise termed as biotolerant and hence do not induce any interfacial biological bond between the implants and bone. ${ }^{7}$ The chemical inertness of these materials results in the formation of a very thin layer of acellular collagen capsule at the interface, isolating it from the body. The thickness of this fibrous layer depends on several factors, both on the tissue side (tissue type, health/age of the tissue etc.) and the implant side (composition, porosity, surface morphology, chemical reactions, etc.). ${ }^{5,8}$ They formed the first generation of hard tissue replacements, which was later on replaced by bioactive and bioresorbable materials. ${ }^{8}$ Hydroxyapatite, bioglass and glass ceramics are bioactive in 
nature, forming direct chemical bonds with bone, or even with the soft tissue of a living organism. ${ }^{2}$ Bioresorbable ceramics (tricalcium phosphate) are eventually replaced by the host tissue, or it may later on actively participate in the metabolic processes. ${ }^{6,9}$ Over the years, these diverse classes of bioceramics progressed as an alternative to metals, in terms of their bioinertness and processablilty. ${ }^{10}$ They can be produced in a variety of forms and phases, usually as powders in restorative materials in dentistry, or as inert coatings that are thromboresistant and corrosion protective, or most widely as bulk implants, prostheses or prosthetic devices, that can directly bond with tissues for skeletal repair and reconstruction. ${ }^{5}$ Conventional processing routes, such as liquid-phase sintering, solid-state sintering, hot pressing and the sol-gel method are commonly employed to fabricate fully dense, relatively inert crystalline ceramics. ${ }^{5,10}$ Spark plasma sintering is an alternative method to high temperature conventional technique of bioceramics, making the consolidation of a powder compact possible at lower temperatures and shorter duration by charging the intraparticle porous region with electrical energy and efficiently applying a high temperature spark plasma momentarily. ${ }^{11-13}$ Currently, with the rapid advancement of modern solid free form fabrication techniques, like three-dimensional printing, stereolithography, fused deposition modeling, robocasting and phase-change jet printing, it is possible to produce complex biomimetic and patient specific 3D porous scaffolds that permit the desired tissue ingrowth and vascularistaion. ${ }^{14-16}$

With the advent of many biomaterial compositions, it has become the prime focus of this field to ensure the safety of the newly developed or currently used material, by proving its biocompatibility and understanding its toxicological profile. ${ }^{17}$ The risk assessment of bioceramics becomes a critical issue because of their intended use in intimate contact with the tissue for a longer period. ${ }^{25}$ The ideal approach for a biocompatibility evaluation is to test the material on human subjects, but this is complicated, due to legal and ethical considerations. In order to provide various therapeutic solutions for various human diseases, clinical testing can be conducted with materials, only after successfully completing the first three phases of biocompatibility testing recommended by the ISO (International Organization for Standardization) guidelines. ${ }^{18}$ As a permanent replacement of diseased tissues in human bodies, the compatibility of biomaterials directly affects the response of nearby tissues. Besides the cytotoxicity and histotoxicity, the detection of genotoxicity has become a necessary process to evaluate composite materials. ${ }^{19}$

Government agencies and regulatory bodies such as the ISO and the FDA (Food and Drug Administration) provide procedures, protocols, guidelines, and standards that may be used for the biocompatibility evaluation of newly developed materials. ${ }^{20}$ Depending on the nature and duration of the contact of a biomaterial with an osseous system, an appropriate set of standards are recommended by the ISO. The first part of the guideline, ISO10993-Part 1, provides the methodology for choosing the proper biological evaluation tests. It also includes vital information about the positive and negative control materials, extraction conditions, choice of cell lines and cell media, as well as important aspects of the test procedures, including tests on extracts, and tests by direct and indirect contact. ${ }^{21,22}$ Part 2 explains the animal welfare requirements, and Parts 3 presents the guidelines for specific test procedures or other testing-related issues. ${ }^{5,23}$ The FDA follows the ISO guidelines in some areas, but the test procedures and requirements vary slightly between the two. Generally, all nonclinicallaboratory studies, including in vitro and in vivo experiments, for biomaterials that are intended for human use should comply with the Good Laboratory Practice (GLP) regulations. Hence, it is important to note that the biocompatibility validation studies should obey the GLP regulations for any regulatory approval. ${ }^{23,24}$ The standards and guidelines for evaluating the biocompatibility of materials are continually updated or modified, according to new scientific advances, or to prevent the recurrence of problems that have arisen in the past.

It is known that the implantation of biomaterials causes a cascade of reactions in the biological environment. The host tissue, together with the physical properties of the biomaterials, determines the biocompatibility and the longevity of the implants. Therefore, understanding the phenomena of the biological interaction of a biomaterial serves as an important aspect in evaluating the stability of an implant. Various issues, such as the improper choice of an analytical determination test and a lack of knowledge in choosing an appropriate quantity of the test substance limits the complete evaluation of medical implants. ${ }^{25}$ Although there will be a small level of tissue injury during the implantation for biocompatible implants, usually a steady state is reached during the restoration process, aiding in the continuous performance of the implant. However, due to prolonged leakage of toxic substances from the implants into biological fluids, it will induce persistent inflammation. This will interfere with the fusion and performance of the implant. ${ }^{20}$ To avoid such anomalies, the potential toxicity of a biomaterial should be evaluated before clinical use in vitro and in vivo. ${ }^{32}$ The lengthy chain process of translating the developed biomaterial from laboratory bench studies to a consistently reproducible and stable product for a clinical trial still faces many hurdles and difficulties. For a newly designed biomaterial to move from the lab to the clinic, it must go through rigorous phases of tests, which are mentioned in a nutshell in Fig. 1. After the biomaterial is screened through a series of in vitro biocompatibility testing and found to be non-toxic, it is recommended that such a material undergoes clinically relevant in vivo osseointegration tests. The in vivo tests essentially involve implanting the material in an animal model and the evaluation of its histocompatibility. This is followed by clinical trials in human patients. Both the animal and human trials mandatorily require approval from the institutional ethics committee.

This review highlights concisely the past and present strategies used in evaluating the compatibility of newly developed bioceramics, along with some case studies, showcasing the assay methodology to be followed during the toxicity assessment. Besides the bulk material compatibility, the need to study the toxicological implications of wear particulates is also discussed briefly, with special emphasis on the appropriate evaluation tests, to ensure the long term safety of the materials under physiological conditions. 

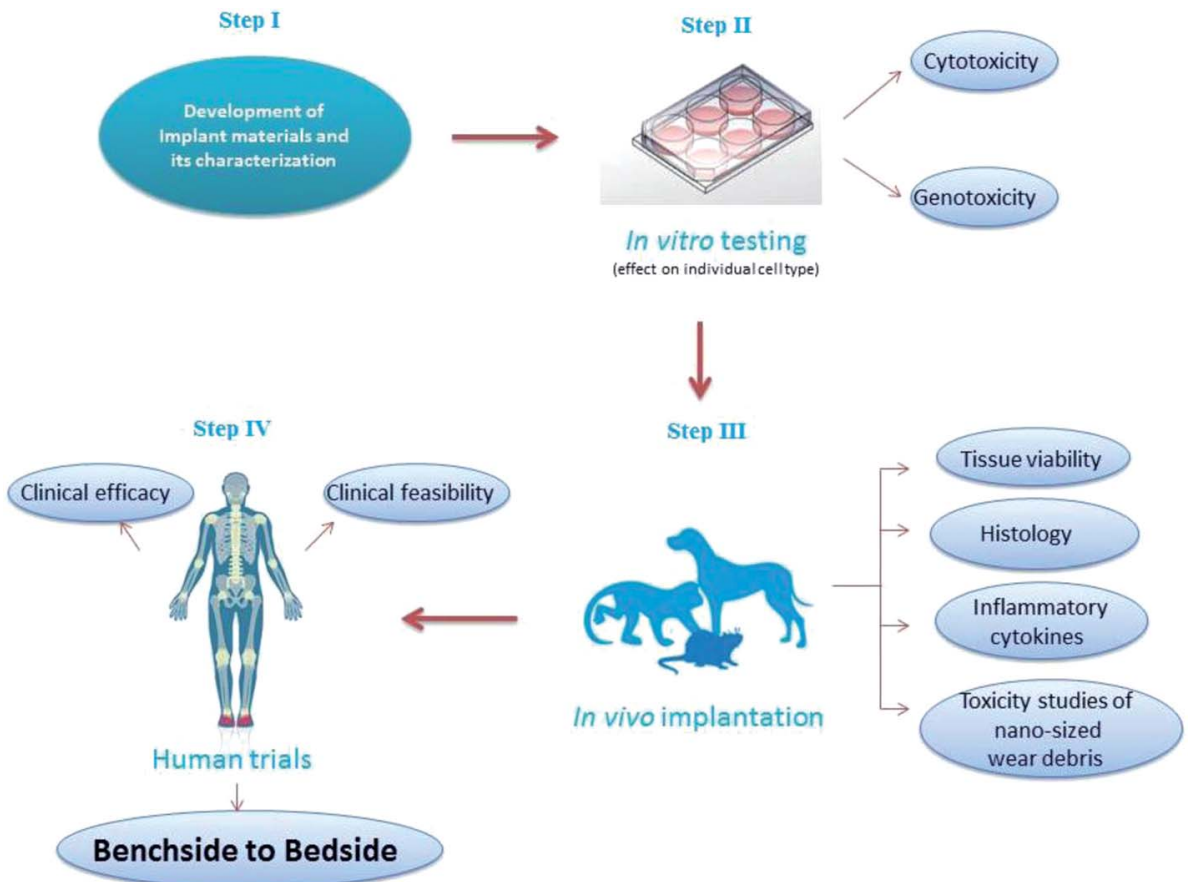

Fig. 1 Brief overview of the steps involved in the translation of newly developed biomaterials from benchside to bedside.

\section{Evaluation of bioceramic toxicity}

Depending upon the anatomical location in the body, metals, ceramics, polymers and their composites with acceptable biocompatibility are being used as artificial implants. ${ }^{26}$ Amongst these three material classes, ceramics are the most commonly used materials in dental and orthopedic applications to restore damaged hard tissue. ${ }^{27}$ As the biocompatibility of any material used in the human body is a crucial property, tests to ensure the biological compatibility of materials have been specified by regulatory organizations. A poorly tested biomaterial once implanted may stimulate a chronic biological reaction that depends both on the implant surface and also the host tissue. In the present scenario, a material is considered to be safe if it is proven to be cytocompatible in vitro. In vitro tests are always appealing, due to the lower cost, shorter time duration, and higher reproducibility and reliability. Since, in vitro tests only expose single cell types in a culture, these results cannot be directly related to the outcome in a complex biological system (living tissue). ${ }^{28}$ Hence, to have a long term clinical performance, along with studying the cell/tissue reactions to an implant, a series of risk assessments has to conducted on the proposed biomaterials, such as oxidative stress, necrosis/apoptosis, inflammation, genotoxicity, degradation/ metabolism, immunogenicity, organ distribution, cellular recognition/internalization, clearance and excretion. Such an array of assessments is necessary to completely understand the nature of the toxicity of the material. ${ }^{29}$ In addition, depending on the duration of the material interaction with the body, different tests have to be selected to ensure the biocompatibility. ${ }^{30}$

\subsection{Cytotoxicity}

The cytotoxicity of a proposed material to a specific cell type can be studied either by directly seeding the cells on the surface of the material, or by exposing the cells to the extraction fluid, which falls under an indirect toxicity evaluation. ${ }^{31}$ The choice of assays used will always influence the evaluation of the cytotoxicity of any biomaterial. ${ }^{32}$ The selection of other parameters, such as cell lines, controls, biochemical assay type and time of culture are all crucial, while evaluating a material's compatibility. ${ }^{33}$ Prior to studying the tissue response of a material in vivo, it is always recommended to conduct a preliminary in vitro study to obtain some insights about its behavior in a biological environment. As an example, the cytotoxicity study using multiple cell lines, such as a mouse fibroblast cell line, mouse epithelial cell line and human keratinocyte cell line on three different polymeric biomaterials did not reveal any statistically significant difference with regard to the sensitivity of the cell lines for the toxic residues. ${ }^{31}$ In contrast, Park et al. reported that among the 13 cell lines (of different tissue origin) used to detect the cytotoxic effect of a polyurethane film containing $0.1 \%$ zinc diethyldithiocarbamate, the material showed a variable cytotoxic potential that was related to the cell type. This reiterates the fact that the cell-line dependent sensitivity is crucial to measure the toxic response and hence, a combination of two or more evaluation methods along with specific cell lines should be used in accordance with the test materials for in vitro cytotoxicity testing. ${ }^{34}$

Additionally, the selection of cell types should be based on the specific applications of the material under investigation. For instance, Schwann cells and neuroblastoma cell lines can 
be used to assess the in vitro cytotoxicity of materials used for nerve regeneration. ${ }^{35}$ Similarly, human fetal osteoblast or osteosarcoma cell lines can be used to check the cellular compatibility for orthopedic implant materials, ${ }^{36,37}$ and keratinocytes or fibroblasts can be used for determining the cytotoxic potential of wound dressing materials. ${ }^{38}$ Over the years, it has been recognized that the direct use of cell and colony counting as an assay end-point is probably the least reliable method. Rather, the use of several different end-points might generate more biologically relevant information concerning the nature of the toxicity. ${ }^{32}$ For example, oxidative stress can be monitored by a fluorescent product (DCF assay) generated by the oxidation of the non-fluorescent substrate, H2DCF-DA. Likewise, colorimetric assays such as MTT (3-(4,5-dimethylthiazol-2-yl)-2,5-diphenyltetrazolium bromide) and LDH (lactate dehydrogenase) monitor the cellular metabolic activity and cell death respectively, based on the reduction of lightabsorbing substrates. ${ }^{39}$ Metabolic impairment assays are the most widely accepted ones, because they can detect any reduction in the metabolic viability, which further can be correlated to the proliferative capacity of the cell. ${ }^{\mathbf{4 0}}$ Another qualitative method to determine the viability, proliferation and cell density is the fluorescent based live/dead assay. ${ }^{\mathbf{4 1}}$ The simultaneous staining of live (green labeled) and dead (red labeled) cells on the biomaterial surface reveals the amount of dead cells present, either by visualizing under fluorescence or confocal microscopy. ${ }^{\mathbf{4 2}}$ The list of commonly used assays for evaluating the cytotoxicity of biomaterials is mentioned in Table 1.

Often, conclusions and predictions made from in vitro testing differ considerably, when the materials are placed into or on tissues of the osseous system. Cytotoxicity assays measure the effects on cells during the first 12-24 $\mathrm{h}$ after exposure to the material. The physiological scenario is entirely different, wherein the host cells either recover from, or succumb to their chemical injury. Eventually, other cellular and molecular cascades are switched on, such as inflammatory and immune reactions. ${ }^{43}$ Therefore, multiple biochemical assays are to be used to probe various biochemical signaling pathways involved in the toxicity of bioceramic particulates.

Table 1 Advantages and disadvantages of some cytotoxic assays, usually performed with adherent and non-adherent cell types

\begin{tabular}{ll}
\hline Assay & Advantages \\
\hline Trypan blue $^{190}$ & $\begin{array}{l}\text { A simple and rapid method able to provide } \\
\text { approximate results. }\end{array}$
\end{tabular}

MTT $^{191}$ 3-(4,5-dimethylthiazol-2-yl)-2,5diphenyltetrazolium bromide

MTS $^{192,193}$ 3-(4,5-dimethylthiazol-2-yl)-5-(3carboxymethoxyphenyl)-2-(4-sulfophenyl)2Htetrazolium

$\mathrm{XTT}^{194}$ (sodium 2,3,-bis (2methoxy-4-nitro-5sulfophenyl)-5-[(phenylamino)-carbonyl $]-2 H$ tetrazolium)

WST-1 (ref. 195) (4-[3-(4-iodophenyl)-2-(4nitrophenyl)-2H-5-tetrazolio]-1,3-benzene disulfonate)

LDH (lactate dehydrogenase)

$\mathrm{NRU}^{196}$ (neutral red)

GSH, ${ }^{197}$ glutathione estimation

AlamarBlue ${ }^{198}$
Gives a precise dose-response curve on small cell numbers. Simultaneous testing of different parameters can be done. Simple and high reproducibility.

Simple, rapid, flexible and nonradioactive. Established procedures and several publications.

A single time point measurement. Soluble in culture medium, and is therefore suitable for use with non-adherent as well as adherent cell lines.

No volatile organic solvent is required for solubilization. More sensitive than using MTT. Short reaction time. No need to wash or harvest cells for the assay. Accelerated color development.

Results reflect membrane integrity. Reagent doesn't damage viable cells. Has a long half-life. Can multiplex with any other assay and is fast (usually a 10 minute incubation period). Very sensitive and readily quantifiable. It is at least two times cheaper than the rest of the assays. Does not use unstable reagents as required for the viability tests using tetrazolium salts. Estimation of total cell number by assaying protein content.

Does not use unstable reagents as required for the viability tests using tetrazolium salts. Estimation of total cell number by assaying protein content.

Elimination of the washing/fixing and extraction steps. Incorporation of a fluorometric and colorimetric growth indicator. ${ }^{199}$
Disadvantages

Can be labor intensive, as well as not being able to distinguish between living and dead cells in large quantities. Gives approximates.

Cell unspecific. There is no discrimination between cytostatic and cytotoxic effects. Can have spectral interferences. Requires solubilization step. Disposal of organic solvent. Chemical interference by reducing agents. Around a 1000 cell sensitivity in 96 well format. Requires 1-4 hour incubation period. Cannot collect true zero time control values.

Require the presence of phenozinemethosulfate (PMS) for effective reduction.

Actually measures the net metabolic activity of cells. Cell specific and media specific which one must know how much of the enzyme can be regarded or disregarded as a usable protein.

Not super sensitive. Background contamination via animal serum media. Stop solution addition step involved.

Once started it must be completed immediately.

Once started it must be completed immediately.

Not a direct cell counting technique. High cell number and prolonged culture times will show reversal of the reduction process. ${ }^{200}$ 


\subsection{Morphological evaluation}

The observation of a cell-material interaction on the material surface is regarded as the key determinant for assessing the performance of a new biomaterial. ${ }^{\mathbf{4 4 , 4 5}}$ Cell morphology, adhesion and spreading provide clear indication about the growth behavior and appropriate cellular response to the tested material. ${ }^{\mathbf{4 6 , 4 7}}$ The cell-material interaction can be examined using a multitude of microscopic techniques, including fluorescence microscopy, confocal microscopy and electron microscopy. A high degree of opacity is a major issue in imaging cells attached to the materials, using optical microscopy. ${ }^{48}$ This limitation can be overcome by using powerful fluorescent tools, such as fluorescence microscopy and confocal laser scanning microscopy. ${ }^{49}$ In general, any cellular structures or organelles can be visualized by labeling the cells with specific antibodies/molecules tagged to fluorophores. For instance, cytoskeletal organization is commonly determined by actin staining with fluorescencelabeled phalloidin, which is normally used to assess cell motility, cell spreading, and cell shape. ${ }^{50}$ Besides, a confocal laser scanning microscope has the advantage to probe the cellmaterial interactions by the simultaneous $3 \mathrm{D}$ visualization of both the cell morphology and scaffold architecture. ${ }^{51}$ One major constraint in the confocal laser scanning based imaging technique is the use of a thin sample section, which is necessary due to the limited penetration depth and lower spatial resolution. On the other hand, multiphoton microscopy allows a slice wise optical sectioning and 3D reconstruction, thereby imaging deep into the scaffolds, enabling the label free visualization of cells within scaffolds. ${ }^{52}$ In view of its high resolution, scanning electron microscopy (SEM) is one of the frequently used imaging tools to get an overview of the cell distribution and surface coverage on a tested biomaterial surface. Likewise, the efficiency of cellular seeding, spreading and orientation were mostly imaged under SEM to evaluate the scaffold quality. Even though transmission electron microscopy (TEM) offers the highest possible magnification and resolution, a series of time consuming processing steps and an ultra-thin sectioned sample requirement, makes it a less commonly utilized tool for evaluating cell-material interactions. However, few reports on the visualization of intracellular internalization and localization of nano-hydroxyapatite and the integrity of epithelial cell layers, lamina propria and basement membrane on collagen-glycosaminoglycans-chitosan clearly indicates its power to resolve the ultrastructural subcellular features. ${ }^{50,53}$ Nevertheless, TEM images obtained for biological samples will usually be of low contrast. To solve this problem, scanning transmission electron microscopy (STEM) imaging has been developed, which is solely used to address some of the issues related to biological applications. $^{\mathbf{4 9}}$

\subsection{Gene expression and cytokine levels}

The interactions of cells with biomaterials are estimated using various kinds of techniques with different types of cells. For example, the reverse transcription polymerase chain reaction (RT-PCR) is a very sensitive tool to characterize cellular events at the mRNA level during the cell-material interaction. ${ }^{54}$ The response of cells to various biomaterial surfaces can be analyzed from the mRNA expression profiles of heat shock proteins (HSP). ${ }^{55}$ The HSP 70 and HSP 90 families are a set of highly conserved proteins that play a key role in eliciting cellular activation, as well as the biological responses essential for cellular recovery, survival, and maintenance of normal cell functions. Minimal expressions of HSP indicate that the biomaterial adhered cells are exposed to lesser stress or environmental damage. ${ }^{56}$ In a representative study, HeLa cells attached to the hydrophilic surfaces induced a substantially higher expression of HSP, due to a higher stress level than on the hydrophobic surfaces. The results reflect on the bioinertness of hydrophobic surface, possibly due to less protein adsorption, thereby demonstrating the sensitivity of HSP as a sensitive marker in evaluating cell-material interactions. ${ }^{57}$

The response of the host tissue to implant materials is due to the sequential activation of cytokines that directs either inflammatory or healing reactions. These cytokines also govern the fusion of macrophages to form giant cells, that eventually becomes the culprit for implant failure. ${ }^{58}$ Among a pool of cytokines, the release level of proinflammatory cytokines, such as interleukin-2 (IL-2), interleukin-6 (IL-6), interleukin-8 (IL-8), and tumor necrosis factor alpha (TNF- $\alpha)$, are largely quantified to assess the foreign body reaction at the site of implantation. ${ }^{59}$

\section{Genotoxicity}

The genotoxic effect of implant materials and associated particles is widely considered as an important aspect of the long term safety assessment of the materials in the human body. In toxicity assays, cytotoxicity detection is usually performed before the genotoxicity test, to confirm the threshold concentrations of the experimental implant that inhibits cell proliferation. The possible mechanism of gene level toxicity by nanoparticles is explained with the help of Fig. 2. Wear particles, in view of their ultrafine size (length, scale) can get incorporated into the cytoplasmic space of a eukaryotic cell. SEM revealed that particles in the $0.05-3.2 \mu \mathrm{m}$ size range, and TEM showed that particles in the $5-90 \mathrm{~nm}$ size range, can be accumulated in the periprosthetic tissues isolated from revised alumina ceramic total hip replacements. ${ }^{\mathbf{6 0 , 6 1}}$ This further describes the accumulation of nanometre sized ceramic wear particles in the surrounding tissues, which often remains undetected, due to the resolution limitation of SEM for particles of less than approximately $50 \mathrm{~nm}$ in diameter. The bimodal size range of ceramic wear debris overlaps the size ranges commonly observed with metal particles $(10-30 \mathrm{~nm})$ and ultrahigh-molecular-weight polyethylene (UHMWPE) particles (0.1$1000 \mu \mathrm{m}) .{ }^{60}$ On average, ceramic fragments of variable sizes, in the range $0.1-7 \mu \mathrm{m}$, were generated in vivo at the articulating surfaces of ceramic-on-ceramic prostheses, which appears in most cases as sharp-edged, polygonal yellow-brown particles. $^{62,63}$ An exception to this is the zirconium oxide particles released from bone cement wear, which appeared as round (about $0.5 \mu \mathrm{m}$ ) particles. $^{62}$ It has been reported that these nanoparticles, once internalized, can generate reactive oxygen species (ROS) and thereby cause oxidative stresses. ${ }^{64,65}$ Such 


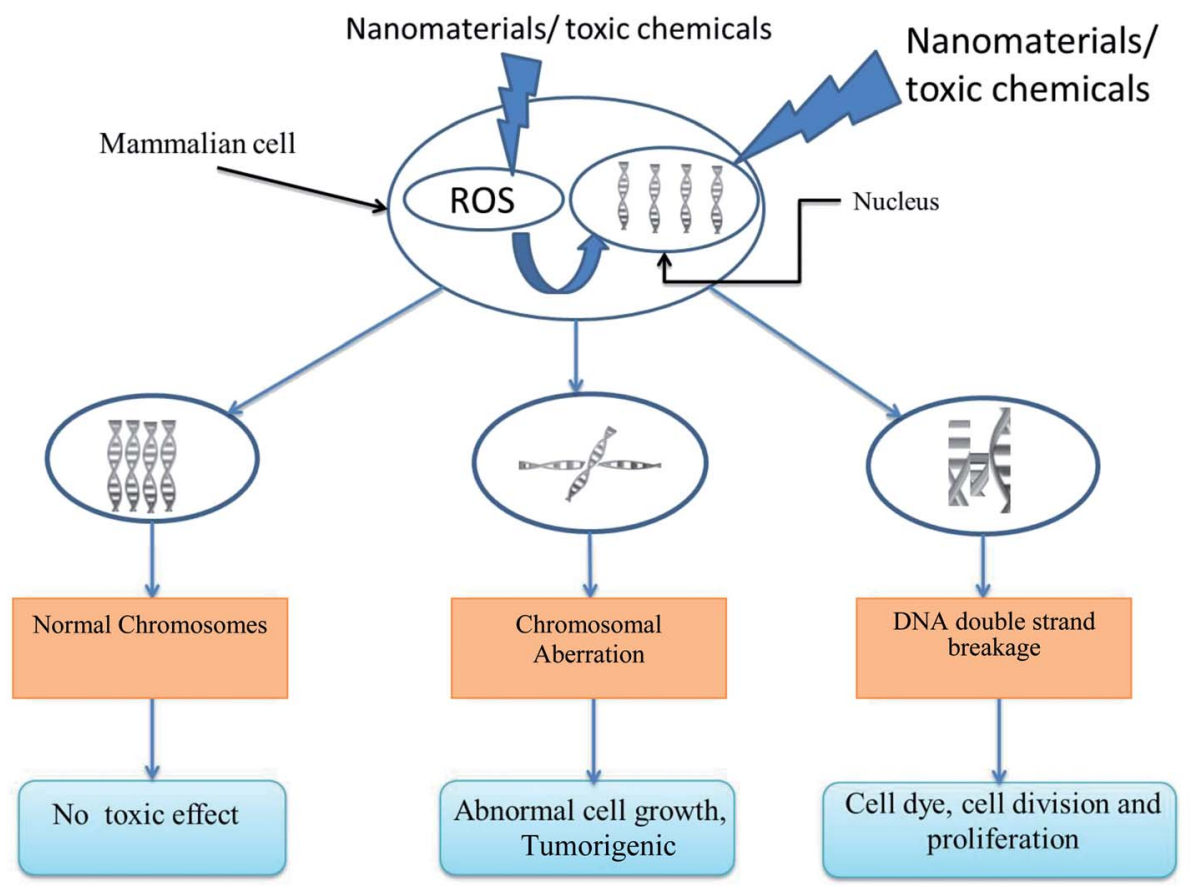

Fig. 2 Schematic representation of the possible mechanisms by which nanoparticles/micron particles entry causes genotoxicity.

processes can further activate various signaling pathways to cause either the aberration of, or double strand breaks of chromosomes in the nucleus, which will adversely affect cell division/proliferation, leading to programmed cell death (apoptosis), as shown in Fig. 2. The influence of oxidative stress to cause genotoxicity is mainly mediated through the upregulation or downregulation of various gene regulatory proteins. ${ }^{66}$ Following exposure to genotoxins, ROS generation acts as a signaling molecule, causing DNA damage ${ }^{67}$ It mainly results in DNA double-strand breaks and replication blocking lesions, leading to the activation of the DNA damage response (DDR) pathway. The phosphatidylinositol-3-kinases ataxia telangiectasia mutated (ATM) and ATR (ATM and Rad3 related) are the key transcription factors that sense this DDR. This in turn activates multiple factors involved in cell cycle control and apoptosis, such as p53, breast cancer-associated protein 1 (BRCA1), NF-kB and AP-1, following genotoxic stress. ${ }^{68} \mathrm{Xu}$ and coworkers $^{69}$ analyzed the upregulation of an array of DNA damage and apoptosis related genes, such as DNA-damage inducible transcript 3 (DDIT3), caspase 1, and cysteine peptidase (CASP1) genes (superoxide dismutase 2, glutathione reductase 1 , etc.), as a result of nanoparticle exposure. Similarly, several apoptosis inhibitors, such as BCL2 interacting protein (HRK), BIK (BCL2-interacting killer, apoptosisinducing), Fas apoptotic inhibitory molecule 3 (FAIM3), apoptosis inhibitor (FKSG2), ST13, GADD45A were all significantly upregulated with nanoparticle treatment. ${ }^{69,70}$ It was also proposed by Xu et al. that the downregulation of CDC14A via a mitosis pathway also plays a role in the potential genotoxicity induced by nanoparticles. ${ }^{69}$

For various cell types, different families of gene regulatory proteins are being activated in the process of genotoxicity. The activation of oncogenes or the loss of the tumor suppressor gene function is one of the main reasons for tumor initiation. The identification of such carcinogenic effects of biomaterials using relevant in vitro approaches is required to be included in the compatibility testing regime. ${ }^{71} \mathrm{~A}$ variety of metals used in orthopedic implants has been demonstrated to induce carcinogenesis in vivo, especially particulates of cadmium, cobalt, cobalt-chromium alloy and nickel. ${ }^{72}$ In a comparative test study, among various implant materials (316L stainless steel, nickel alloy, Ti-6Al-4V, hydroxyapatite-coated Ti-6Al-4V, alumina and zirconia), for the risk of carcinogenicity in mice, only a nickel-alloy induced malignant fibrosarcoma at the site of implantation. ${ }^{73}$ Furthermore, a case study reports the development of osteosarcoma in a human patient at the site of a cobalt-chromium hip implant. ${ }^{74}$ Out of the large number of patients with metal implants of complex composition, a total of 35 cases have been reported to have developed neoplasm and soft tissue sarcoma in the region of implantation. ${ }^{75}$ Still, speculations exists on whether the occurrence is coincidental, or induced somehow by the implant itself, or implant-related modifications of the surrounding environment. ${ }^{76}$ So far, limited studies have reported the carcinogenicity of bioceramics at the site of implantation. An Ames test and carcinogenic/mutagenic tests conducted on alumina and zirconia ceramics confirmed that these materials did not elicit any in vitro carcinogenic effects. ${ }^{77}$ However, in one particular study, the subcutaneous implantation of solid and porous disks of alumina in a rat induced sarcoma at an incident rate of $\leq 25 \%$, which was significantly lower than the tumor incident rates reported in the literature for metals and medical-grade plastics. However, the same tests with ceramic particles did not produce any risk of neoplasms. ${ }^{78,79}$ 
As far as the materials aspect is concerned, hydroxyapatite (HA) has been widely used as dental implants and coatings, due to its resemblance to the mineral composition of bone and teeth. The cells and tissues are constantly exposed to this material, as it takes more than a decade for the complete biotransformation of HA in the human body. ${ }^{80}$ In such cases, it is important to evaluate their mutagenic activity, in order to avoid the risk of mortality after implantation. ${ }^{81}$ It is known that HA particles of different sizes and shapes are used to cure tumors, as it can cause DNA damage and an increased intracellular level of $\mathrm{Ca}^{2+}$. As far as the size effect is concerned, nano hydroxyapatite (nHA) particles, of size ranging from $20 \mathrm{~nm}$ to $80 \mathrm{~nm}$, were found to be effective in inducing apoptosis and cytotoxicity, with the best efficiency around $45-50 \mathrm{~nm}$ sized particles. ${ }^{82}$ Specifically, needle and plate shaped nHA induced the most significant cell death, compared to spherical and rod shaped particles, but with the least particle-cell association. ${ }^{83} \mathrm{~A}$ similar investigation by $\mathrm{Xu}$ et $a .^{84}$ also showed a greater induction of cell injury and increased apoptotic rates by needleshaped and short rod-like particles than the spherical and long rod-like particles. This indicates that nHA, with smaller specific surface areas, causes lower apoptosis and cellular damage.

It was found that nano apatite treated carcinoma cells showed a decreased expression of one of the oncogenes, c-myc and the upregulated expression of p53 genes, which are involved in the suppression of tumors. ${ }^{85} \mathrm{~A}$ study by Sun et al. ${ }^{86}$ also showed that DNA damage induced by HA nanoparticles, activates p53 through the phosphorylation of signal proteins. p53 is an important sensor of cellular stress conditions, including DNA damage, hypoxia, survival factor deprivation, mitogenic oncogenes, and telomere shortening. ${ }^{87}$ Active p53 goes on to regulate downstream genes, including P21, Gadd45 and BAX and finally results in growth arrest and apoptosisinduction. ${ }^{86}$ The cells also exhibited chromatin condensation and dispersion, the formation of vacuoles and finally, could cause oncosis in the treated carcinoma cells in vitro. ${ }^{\mathbf{8 8}}$ In contrast, large HA granules of 100-200 micron size, did not induce any chromosomal aberration, when tested in a rabbit model. There was not more than a 50\% reduction in the mitotic index score for the test group, indicating the non-cytotoxic nature of the HA granules. ${ }^{89}$ From the above discussion, it is apparent that the particle size plays an important role in the genotoxicity of biomaterials.

\section{In vitro mechanical property evaluation of bioceramics}

Even though ceramics are prone to brittle fracture, high wear resistance makes them more appealing in total hip replacement applications, than metals and polymers. ${ }^{90}$ Among the clinical issues related to ceramic implants, fatigue fracture and wear remain the major sources of mechanical failure of load bearing implants. ${ }^{\mathbf{9 1}}$ Hence, the in vitro fatigue performance under appropriate tribological conditions is to be evaluated considering the dynamic loading, dimension and shape of the joints, lubricant (similar to synovial fluid) and large number of cycles. ${ }^{91}$ Most often, the mechanical evaluation of bioceramics for biomedical application are tested under ambient atmospheric conditions. However, it is important to carry out all the tests such as fatigue, wear and fracture toughness in physiological saline (PS), which better mimics the in vivo environment. A four-point bend test of alumina exhibited around a $20 \%$ decline in the bending strength in PS, as compared to that in air $^{92}$ with a similar decrease seen in the elastic moduli of $\beta$-TCP scaffolds. $^{93}$ The fatigue-wear approach is one among the in vitro screening methods considered to be accurate for a lifetime prediction in determining the fatigue performance, close to the physiological environment. ${ }^{\mathbf{9 0}}$ The physiological loading, using a multi-axial load profile, is normally applied throughout the fatigue tests. These are more realistic tests, compared to the basic wear screening tests, such as pin-on-disk, pin-on-plate or ring-on-disc. ${ }^{94}$

Despite the fatigue and wear evaluation complying with the American Society for Testing and Materials (ASTM) or ISO guidelines, the failure of the implants long before their predicted lifetime of $\sim 10-12$ years, in the case of bioceramics, is a major concern. ${ }^{92}$ Recent advancements, such as hip joint simulators, enable a more accurate interpretation of the fatigue and wear behavior in clinical situations. These simulators have been developed to simulate the biomechanics of human joints for a given geometric design, under a variety of operating conditions. In the last few years, various simulator designs were developed in order to achieve a similarity between the simulations and in vivo conditions. ${ }^{95}$ Nevelos et al. ${ }^{96}$ reproduced clinically relevant wear rates and wear patterns in a physiological hip joint simulator by the introduction of microseparation of the prosthesis components during the swing phase of the wear simulation. The size of the wear particles from the simulations was similar to the particles generated in vivo at the periprosthetic tissue regions, but with a slight change in the morphology. ${ }^{97}$ Despite considerable research efforts towards the development of new bioceramic materials, the study involving total hip or knee simulator of ceramic based biomaterials is not significant and this requires attention in future.

\section{In vivo studies}

In order to claim a newly developed material as an ideal implant, it must undergo extensive investigation (both in vitro and in vivo) to assess the biocompatibility, mechanical stability and safety. The results from short term in vitro studies can be difficult to extrapolate to the in vivo situation. Moreover, these measure the effect only during the first 12-24 $\mathrm{h}$ after exposure to a toxic substance. However, many biological reactions in vivo are rather complex and continue beyond $24 \mathrm{~h} .{ }^{33}$ For this reason, the use of animal models is an essential step in the testing of orthopedic and dental implants, prior to clinical use in humans. ${ }^{98}$ Moreover, in vivo tests allow the implanted material to come into contact with different cell types and also provide interactions with blood, proteins, enzymes and other hormones. Despite the availability of numerous animal models for testing the biological performance of implants, the choice of a suitable model is always crucial, based on the type of study. ${ }^{99}$ The foremost selection criteria include similarities with humans, both in 
terms of physiological and pathological considerations. ${ }^{100}$ The dimensions, number and size of the implants, to be tested for in vivo studies, should be chosen based on the pathological location, as well as the species of animal..$^{98}$ The short term in vivo studies are carried out approximately up to 12 weeks and small animals like mice, rats, guinea pigs, or rabbits are often used for these studies. In a similar way, animals with a long-life expectancy, such as guinea pigs, rabbits, dogs, sheep, goats, pigs and other animals are suitable for longer-term testing. As the in vivo assessment of tissue compatibility of a biomaterial is focused on the end-use application, it must be noted that a biomaterial considered compatible for one application may not be compatible for another application.

The intervention procedures during implantation causes vascular and tissue damage, leading to a complex inflammatory response, followed by the inception of tissue reconstruction with hemostasis. ${ }^{101}$ The bone-implant interface is formed in a layer $200 \AA$ to $1 \mu \mathrm{m}$ thick, that can be calcified, with the thickness varying as a function of the implant material type. ${ }^{102}$ The evaluation of the local pathological effects after implantation is carried out at both the gross level (radiography) and the microscopic level (histology, histomorphometry and electron microscopy). ${ }^{4}$ Largely, implant-tissue interactions around the implants are evaluated by a histopathological examination of sectioned samples. For instance, the cellular features, such as compact lamellar type bone surrounding the implants with osteocytes and lacunae, can be visualized clearly using light microscopy. Any evidence of connective tissue capsule formation, or inflammatory reactions and macrophage invasion at the implant interface, can also be identified after histological staining.

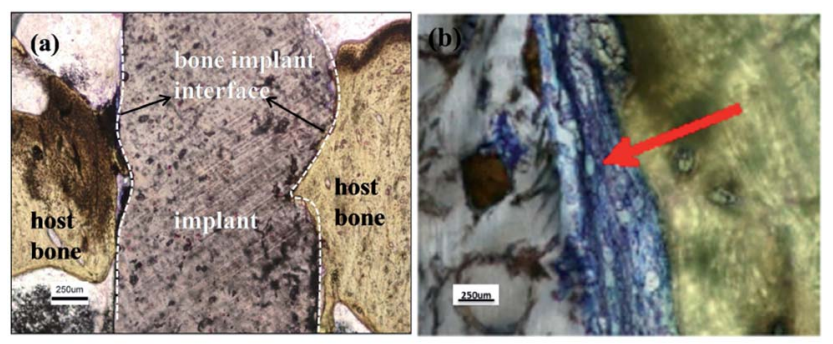

(c)

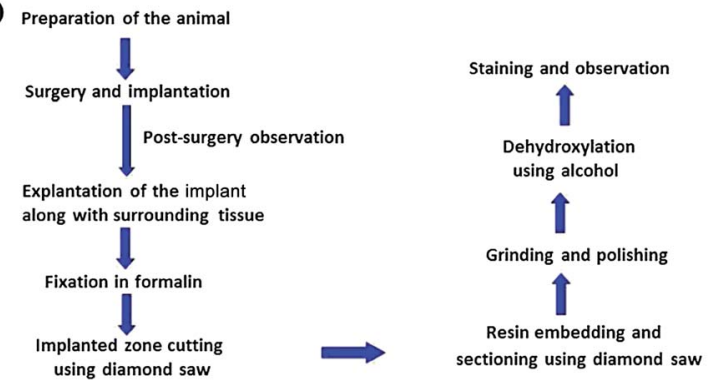

Fig. 3 Photomicrographs of host bone-implant interface (HDPE-20 wt\% $\mathrm{HA}-20$ wt $\% \mathrm{Al}_{2} \mathrm{O}_{3}$ ) after 14 weeks of implantation showing (a) bonding between bone and implant, without implant loosening/ inflammation/implant gap (b) implant interface gap with less bone integration. Red arrow represents the blue stained region showing signs of inflammation and fibrosis. The steps involved in the sample preparation for histopathological examination is briefly mentioned in (c). ${ }^{105}$
Fig. 3a shows an example of the histopathological structure and morphology of neobone formation at the interface between a natural bone and a synthetic polymer biocomposite (highdensity polyethylene- $20 \mathrm{wt} \% \mathrm{HA}-20 \mathrm{wt} \% \mathrm{Al}_{2} \mathrm{O}_{3}$ ). At the end of the implantation period of 4 weeks, a bone segment at the implant site was dissected and processed for histopathological observations (see Fig. 3c). The decalcified thin sections were stained with Stevenel's Blue, that can clearly differentiate between nuclear, cytoplasmic and extracellular components ${ }^{103}$ and counter stained with van Gieson picrofuschin, ${ }^{104}$ for connective tissue fibers. The implant interface gap due to less bone integration is shown in Fig. 3b. The interfacial gap induces inflammation and fibrosis, that eventually hinders neo-osteogenesis (Fig. 3b). ${ }^{105}$

Although normal light microscopy provides the most important information about the presence of bone or soft tissue contact, it does not provide ultrastructural information about the true interfacial arrangement. Piattelli et al. ${ }^{106}$ employed wet SEM, which has similar features to SEM, but with the advantage of avoiding the usual SEM preparation steps, such as dehydrating, degassing, and coating. It was possible to obtain interesting information about bone bonding and apatite layer formation at the interface, yet could not pinpoint the type of tissue around the implant. ${ }^{106}$ The thickness of an apatite layer, its size, orientation and composition can be precisely detected by TEM, as well as with SEM equipped with an electron probe micro-analyzer (EPMA), but with slight artifacts. ${ }^{107,108}$

The two dimensional image obtained after destructive specimen preparation and staining protocols limits the analysis of longitudinal sections (especially for bone), as well as multiple samples. ${ }^{109}$ However, radiographs are commonly used, both before and after implantation, for the evaluation of the host tissue and the tissue reactions around the implants, during follow-up. ${ }^{110}$ It can even provide information about marginal bone loss, but observer variation and a lower resolution can limit the diagnosis. ${ }^{111,112}$ With the advent of the micro-computed tomography $(\mu$-CT) technique, the interface analysis became easier, providing useful information on the morphology, tissueimplant contact, bone area and density profile from the $\mu$-CT values. The characteristics of spongious or trabecular bone that indirectly influences bone strength, such as bone density, trabecular bone thickness and connectivity, can be analytically assessed using $\mu$-CT. ${ }^{113,114}$ This emerging technique also allows a three dimensional analysis, with contrast discrimination up to 1000 times better than that of conventional radiography. ${ }^{115}$

\section{Biological response to wear particulates}

The generation of wear debris and its accumulation in and around the implant are inevitable in the case of many prosthetic systems, due to mechanical stresses, as well as the continuous exposure to body fluids. Several factors influence the progressive wear of particles from the prostheses, such as the implant design, the physiological microenvironment and material parameters. ${ }^{116}$ Severe wear takes place under higher contact 
pressures. When the local stresses exceed the tensile strength of the material, multiple grains will spall from the ceramic matrix, leading to increased wear rate. ${ }^{117}$ The improper fixation of the prostheses and an increased angle of inclination of the acetabular cups have been proved to be a possible reason for accelerated wear. ${ }^{118}$ Moreover, the friction and wear of the implants strongly depend on the surrounding environment. Besides, ceramic wear particles may be trapped between two moving surfaces, causing three-body wear in the physiological environment. ${ }^{119}$ Inside the human body, the implant is continuously exposed to a corrosive mixture of extracellular fluid, comprising water, complex organic compounds, various ions, proteins, enzymes etc. ${ }^{\mathbf{1 2 0}}$ The exposed surfaces will undergo chemical dissolution/degradation, either by the body fluids or by the foreign body reaction, elicited by invading immune cells. The degree and nature of the inflammatory cellular response depends on the material composition, surface structure, surface chemistry and so on. ${ }^{121}$

The important prerequisites required for achieving a lower wear rate in load bearing and articulating (hip joint) implants are extreme hardness, a fine-grained microstructure and a smooth surface finish. ${ }^{122}$ The most clinically accepted wear couple is the combination of an alumina head and an alumina cup (hard/hard), articulating against itself. This ceramic-onceramic bearing surfaces offer considerable advantages over more traditional articulations, which utilize UHMWPE as a bearing material, both in terms of the wear volume and osteolytic potential. ${ }^{\mathbf{1 2 2}}$ In contrast, the wear rate of zirconia articulating against itself was found to be high, which was 5000 times greater than that of alumina. ${ }^{\mathbf{1 2 3}}$ The low thermal shock resistance of the zirconia ceramic discs was thought to be responsible for the extensive cracking and loss of the material. ${ }^{\mathbf{1 2 2}}$ Similar catastrophic wear rates were found for the combination of medical grade alumina/zirconia. ${ }^{122}$ As a first step towards the toxicity assessment of ultrafine particles, the synthesis of such finer particulates from bulk materials without a compositional change is an important aspect. Once such particles are prepared, one can prepare an eluate by dissolving such particles in phosphate buffered saline (PBS) or other medium. The stages involved in eluate preparation from a bulk biomaterial are shown in Fig. 4. Furthermore, Fig. 4 shows the recommended sequence of various biochemical assays to evaluate the toxicity potential of biomaterial eluate.

To the best of our knowledge, there is no unambiguous evidence in the literature which can suggest the critical concentration of particles, irrespective of the chemical composition. Similarly, we do not have any clear literature proof indicating the size of the particle that will be toxic, if generated in vivo. The biological response to wear particles is a complex interaction and multiple variables, like size, concentration, shape and composition influence such interactions. With regard to the composition, high-density polyethylene (HDPE) particles showed a significantly higher inflammatory response, compared with alumina particles of similar size and concentration, implying that in addition to the ability of macrophages to respond to the size and concentration, these cells are sensitive to the composition effect. ${ }^{\mathbf{1 2 4}}$ In another study, the volumetric concentration of alumina particles required to stimulate an inflammatory effect was found to be extremely high $\left(500 \mu \mathrm{m}^{3}\right.$ per cell). However, it is unlikely to achieve such threshold concentration in vivo, due to the extremely low wear rates $\left(<4 \mathrm{~mm}^{3}\right.$ per million cycles) of ceramic-on-ceramic prostheses, even under severe microseparation conditions. ${ }^{\mathbf{1 2 5}}$ Another report suggests that the osteolysis due to wear particles is more likely to occur when the wear rate is more than $0.1 \mathrm{~mm}$ per year and its occurrence is least expected for the wear rate of less than $0.05 \mathrm{~mm}$ year. ${ }^{126}$

The wear products generated in vivo can disseminate via the lymphatic system and can either remain inert, or can induce a carcinogenic or mutagenic effect. ${ }^{127}$ The material toxicity arises mainly from the ions leaching out from the wear debris. In vivo, the wear rate of a ceramic-ceramic is 4000 times less than that of a metal-polymer. ${ }^{128}$ Due to the particle exposure, macrophages and fibroblast-like cells, from the synovial fluid, release prostaglandins, metalloproteinases, and cytokines, stimulating inflammation, causing aseptic loosening. IL-1, IL-6 and the metabolite $\mathrm{PEG}_{2}$ are potent inducers of osteoclast activation and resorption in the joint area. The long-term exposure of zirconia and alumina powders to synoviocytes slowed its proliferation rate without any significant change in the release of IL-1 and IL-6, but to a small extent inhibited the functioning of some of the metabolites associated with lipoxygenase pathways. ${ }^{129}$ Zirconia and alumina are the two ceramic materials widely used as load bearing implants, due to their bio-inertness

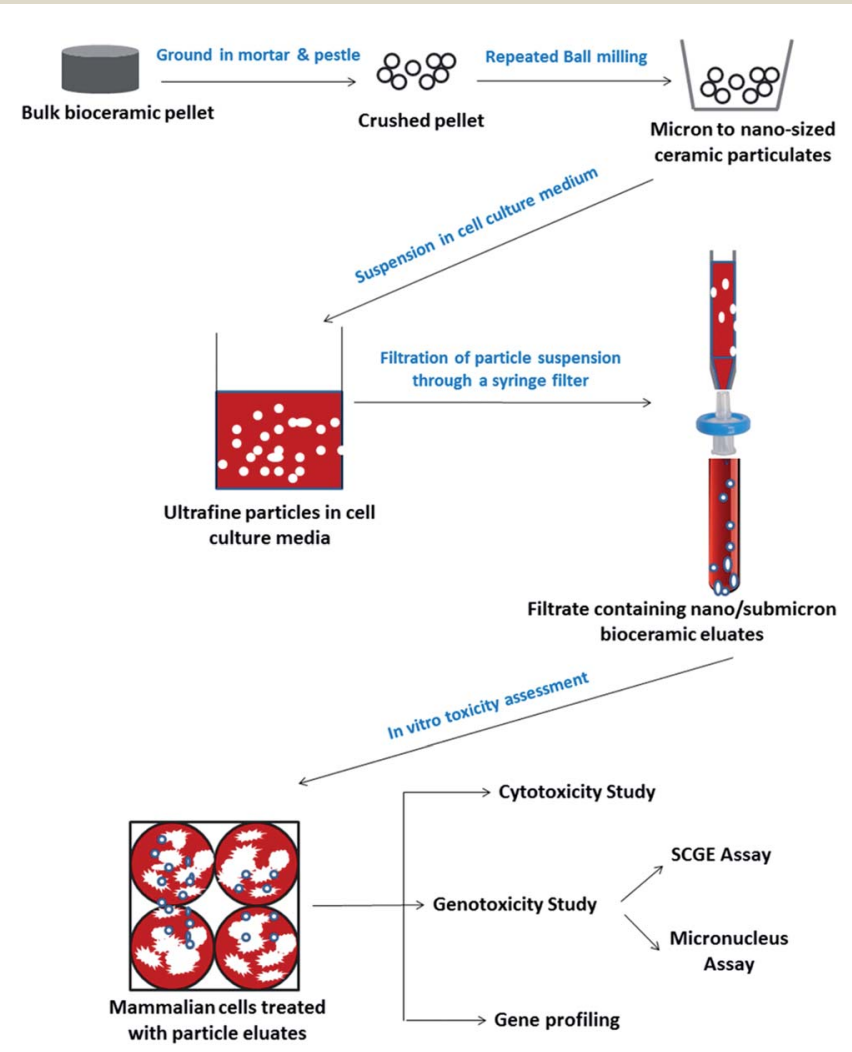

Fig. 4 Schematic illustration showing how nano/submicron particulates can be prepared, from starting bulk materials to study the toxicity of biomaterial eluates. ${ }^{176}$ 
and stability, that can meet the criteria at the loading parts of the human body. Wear particles that are of a few microns in size can cause cellular reactions in the biological environment. To this end, the larger release of yttrium and zirconium ions from an yttrium-doped zirconia in a dissolution test, using lactic acid, indicate the non-suitability of these materials in a lower $\mathrm{pH}$ environment, especially as dental implants. ${ }^{\mathbf{1 3 0}}$

It is well known that bulk HA is highly bioactive, whereas the dissolution of HA particles and the diffusion of ions into the cells can affect the survival of the tissues. In an attempt to study the effect of various HA powders on the monocyte intracellular element concentrations, Laquerriere et al. ${ }^{\mathbf{1 3 1}}$ employed an X-ray microanalysis technique to measure the elemental concentration of diffusible ions such as $\mathrm{P}, \mathrm{S}, \mathrm{Mg}, \mathrm{K}, \mathrm{Na}$, and $\mathrm{Cl}$ as markers, to identify the cytotoxicity in cells. Among them, the most observed criteria was the $\mathrm{Na} / \mathrm{K}$ ratio, which is an indicator of the viability, with a smaller value signifying a higher material toxicity. ${ }^{\mathbf{1 3 1}}$

Even though it is well documented that the particulate toxicity might be associated with multiple modes of cell death, toxicity was initially thought to be of the necrotic type. Later, several studies showed apoptosis as the predominant mode of cell death, exerted by chemical or nanoparticle toxicity. ${ }^{\mathbf{1 3 2}}$ Apoptosis is a mechanism of programmed cellular death, involving cellular shrinkage, nuclear condensation and DNA degradation, caused by the selective activation of endonucleases. ${ }^{133-135}$ This process is accompanied by fragmentation of the cell into membrane-bound apoptotic bodies, which are rapidly up taken by phagocytosis in macrophages, dendritic cells or parenchymal cells. ${ }^{136}$ The integrity of the plasma membrane of cells undergoing apoptosis is preserved and most functions of the membrane remain unchanged. ${ }^{\mathbf{1 3 4}}$ The stage wise morphological changes, as well as the biochemical changes during apoptosis are summarized in Fig. 5a. During this process, a cascade of signaling proteins is activated, leading to apoptotic induction. ${ }^{137}$ Of them, the Bcl-2 family of regulatory proteins, has an anti-apoptotic effect, by controlling the membrane integrity. An excess of pro-apoptotic protein, Bax and a decrease of Bcl-2 at the surface of the mitochondria, permeabilizes the outer mitochondrial membrane and triggers the release of cytochrome $\mathrm{c}^{\mathbf{1 3 8}}$ Cytochrome c release into cytosol leads to the activation of the caspase cascade. The preceding proteolytic activity induces cellular DNA damage and apoptosis. ${ }^{139}$ Fig. 5 b elucidates the key molecular mechanisms involved in the apoptotic pathway.

An extremely low level of heat generated by metabolically active cells can be used as an evaluation tool for the continuous monitoring of the growth and activity of cells that interact with biomaterials. ${ }^{\mathbf{1 4 0}}$ Isothermal micro-nanocalorimetry (IMNC) is a passive detection technique, having the capability of measuring the heat production of growing and proliferating cells in the $\mu \mathrm{W}$ range. Hence, it has the advantage of studying the fate of cells after treatment or exposure, without disturbing the cells culture. ${ }^{141} \mathrm{Ca}^{2+}$ ions leaching out from glass and HA affect the energy metabolism in a significant way. However, human chondrocytes grown in contact with a bioactive glass and HA particles did not alter the heat production, as detected by IMNC, proving its minimal effect on the metabolic activity of the cells, even at a concentration of $3 \mathrm{mg} \mathrm{ml}^{-1}$.

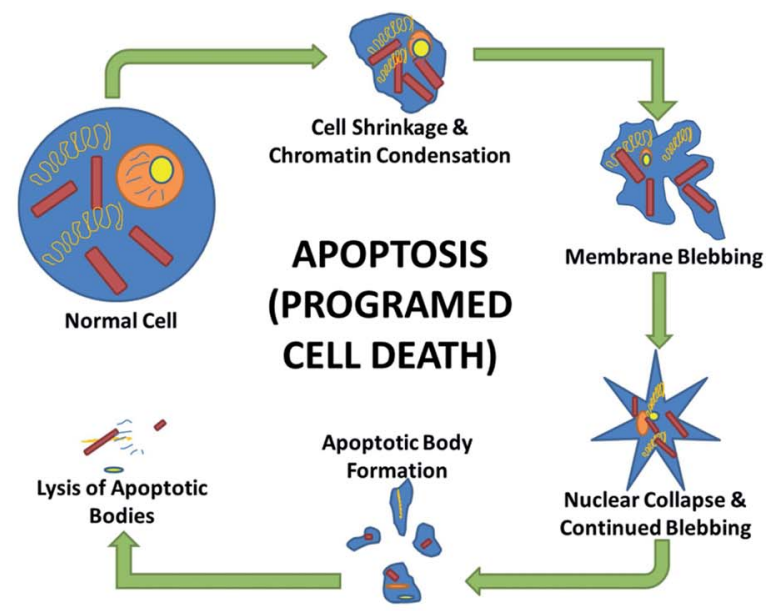

(a)

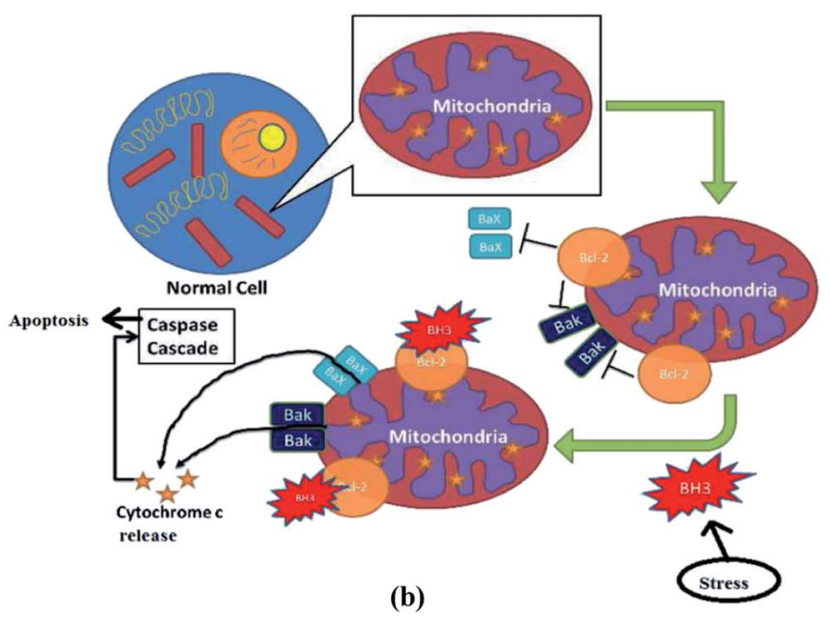

Fig. 5 Diagram of (a) step-by-step process of apoptosis and (b) molecular mechanism of apoptosis.

The surface to volume ratio for bioceramic nanoparticulates is higher in comparison to microparticulates and hence has improved properties, like osseoconductivity, but also has higher solubility and exhibits a higher ion release rate. Considering this fact, there is a greater possibility that such particles may induce cellular and genetic damage. In general, for all tested bioceramic particles, the DNA damage increased with increasing concentration. According to Tavakoli et al., ${ }^{142}$ a higher percentage of DNA damage and higher tail migration were detected using a single cell gel electrophoresis (SCGE) assay, for a concentration of more than $4 \mathrm{mg}$ $\mathrm{ml}^{-1}$ of a novel nano bioactive glass, after $24 \mathrm{~h}$ of treatment in fibroblast cells. This shows that the genotoxicity of any material depends on the concentration, and the optimal test concentration has to be decided based on the type and extent of patient contact. ${ }^{\mathbf{1 4 1}}$ For instance, if the developed material is a potential substance for dentistry, then higher concentrations of material are needed to be tested, because most dental materials release small amounts of various substances into their physiological environment, like the pulp and the oral cavity. ${ }^{131}$ 
Among other forms of apatite, widely used in hard tissue repair and replacement and at the same time has raised toxicity concerns, is fluorapatite (FA), since the $\mathrm{F}^{-}$ions released from this inorganic composite can induce genotoxic and mutagenic effects. ${ }^{143}$ Eluates of FA treated on Chinese hamster V79 cells had an anti-proliferative effect, due to DNA breakage and genome disintegrity, but conflictingly had no detectable mutagenic effect. Similar G0/G1 arrest and inhibition in the cell proliferation were found in FA treated NIH-3T3 cells, revealing the harmful genotoxic effect of fluoridated biomaterial eluates. ${ }^{\mathbf{1 4 3 , 1 4 4}}$

Heil et $a{ }^{17}{ }^{17}$ reported a thorough study on the mutagenesis/ carcinogenesis of dental material extract, using three fast and reliable test systems, namely the bacterial umuC-test, the eukaryotic DNA synthesis inhibition test and an in vivo alkaline filter elution technique. The bacterial umuC test, using the Salmonella typhimurium strain, is as sensitive as an Ames test, with a umuC operon capable of being induced by genotoxic agents. This can be directly assessed from the activity of $\beta$-galactosidase, whose gene is fused along with the umuC operon. Similarly, DNA damage is the main cause of carcinogenesis and therefore detecting carcinogenic substances released from an implant also comes under the preliminary evaluation of the newly developed biological implants. It has been widely reported that the micronucleus test (MNT) specifically detects chromosomal damage, caused by toxic materials. ${ }^{145}$ A large number of reports indicate that the in vitro MNT shows proper sensitivity and specificity for the detection of new material genotoxicity. Micronuclei occur when cell division is hampered by chromosomal breaks. Hence, they cannot distribute during division and form the micronuclei. In a study to check the genotoxicity of $\mathrm{HA} / \mathrm{ZrO}_{2}$ composite particles, it was found that the micronuclei ratio significantly increased with an increase in the proportion of $\mathrm{ZrO}_{2}$ beyond $70 \mathrm{wt} \%$, at a concentration of $200 \mu \mathrm{g}$ $\mathrm{ml}^{-1}$ concentration. However, in such conditions, an appropriate proportion that is well below the toxic concentration can be used in developing substitutes for bone replacement. ${ }^{145}$

\section{Cytotoxicity examples of bioceramics and its eluates}

Hydroxyapatite ceramics have long been recognized as appropriate substitute materials for bones, due to their chemical and biological similarity to human hard tissues. ${ }^{\mathbf{1 4 6}}$ However, they lack the required strength and toughness for load bearing implant applications, even though they support bone ingrowth/ osseointegration. To improve the mechanical properties based on the excellent biologic activity, different HA-based composites, as well as HA coating on the surface of metallic implants, are currently used. ${ }^{14-149}$ Even though different coating process are continuously being investigated to deposit HA, with optimal coating properties for implant success, it is generally accepted that plasma-sprayed HA coatings improve the bone strength and initial osseointegration. However, the optimum coating properties required to achieve a maximum bone response have yet to be achieved. ${ }^{150}$

\subsection{Hydroxyapatite-titanium composites}

Titanium (Ti) is an extensively used orthopedic implant material, due to its low density and excellent corrosion resistance. ${ }^{151}$ The development of biocomposites based on HA and Ti, having enhanced physical properties and biocompatibility, acts as a better alternative for bone substitutes. With this fact in mind, our group developed HA-Ti composites, with Ti varying from $5 \mathrm{wt} \%$ to $20 \mathrm{wt} \%$, using the spark plasma sintering technique. ${ }^{152}$ The physical properties of HA-Ti, in terms of hardness, elastic modulus and fracture toughness were made similar to the cortical bone. Along with this, the aspect of biomineralization, as well as the quantification of osteoblast cell fate processes on these composites were also analyzed critically. ${ }^{152}$ The routine biochemical analyses that are used to identify cell viability cannot predict whether the mode of cell death is due to apoptosis or necrosis and therefore, other molecular biology techniques are being used, lately. Fluorescence-activated cell sorting (FACS) analysis can precisely distinguish between an apoptotic/necrotic cell and the principle of this analysis uses a single-cell based fluorescent detection. ${ }^{153}$ Furthermore, the data obtained from biochemical assays indirectly reflect the proliferation and cytotoxicity, with many measurement errors, by providing only the baseline information. Flow cytometry measures the physical characteristics of single particles/cells, when exposed with a laser in a fluid stream. The sorting of the cells is based on tagged fluorescent molecules. The fluorescent tagged cells are sorted with a laser as the cells move past a set of stationary detectors. Overall, in the biomaterial research field, the usefulness of flow cytometry in evaluating the cell cycle/ proliferation/apoptosis of cells on material surfaces has not been explored extensively. Cell proliferation of hFOB cells on HA-Ti biocomposites was quantitatively analysed by labeling, using the CellTrace $^{\mathrm{TM}}$ violet dye, wherein the sequential reduction of the fluorescent intensity during cell division is quantified by FACS. Therefore, the division history of each individual cell can be obtained and the average number of cell divisions that the proliferating cells undergo is given by a parameter, termed the proliferation index. Fig. $6 \mathrm{a}$ and $\mathrm{b}$ show the distinct fluorescent intensity peaks of proliferation for HA and HA with $10 \% \mathrm{Ti}$, for different time points, starting from the day of seeding till the 8th day. The parameters, like the proliferation index and division index, were also calculated to assess whether the $\mathrm{HA}-10 \% \mathrm{Ti}$ equally promotes the proliferation/division of osteoblasts, similar to the monolith HA. Therefore, this study presents the efficacy of flow cytometry in analyzing the cell fate processes of a cell population grown on a biomaterial substrate.

It is known that HA and $\beta$-tricalcium phosphate ( $\beta$-TCP) ceramics are brittle and cannot be used as implants in load bearing applications. Therefore, the current practice is to coat load-bearing implants with HA and calcium phosphate, with the intention to induce a rapid implant stabilization in the bone and surrounding tissue. ${ }^{154}$ Coating titanium implants with HA has been suggested to increase osseointegration, by stimulating early osteoblast function. ${ }^{155}$ Recently, the biomimetic deposition of calcium phosphate from simulated body fluids (SBF) has been shown to be an effective method of coating many different 


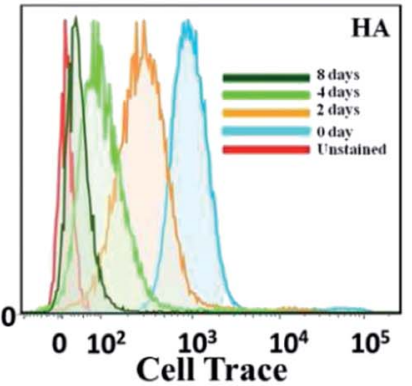

(a)

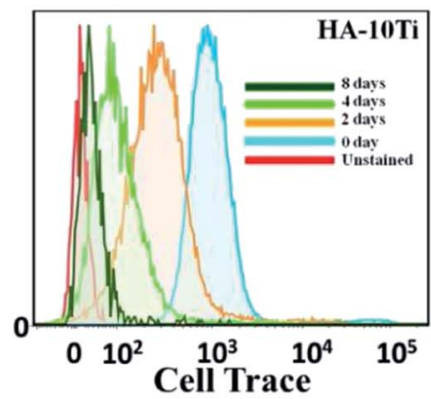

(b)

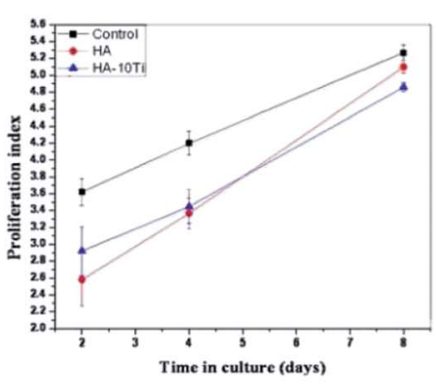

(c)

Fig. 6 Representation of flow cytometry data, showing the proliferation of hFOB 1.19 cells incubated for various time periods. Graphical representations of flow cytometry data, showing the cell proliferation viz. dye reduction for (a) HA and (b) HA10Ti and proliferation index (c). ${ }^{152}$

types of implant materials, to promote osseointegration and bone regeneration. ${ }^{156}$

\subsection{HA-zinc oxide}

Developing prosthetic implant materials that are resistant to bacterial infection has always remained a major challenge among biomaterial researchers. The addition of any antibacterial compound to HA can degrade its cytocompatibility to a significant level and it is widely recognised that an optimum combination of the cytocompatibility and antibacterial properties is ideally desired for bone replacement applications. In this backdrop, our research group has tailored the addition of zinc oxide ( $\mathrm{ZnO})$ to $\mathrm{HA}$, to develop a composite that can compromise between the antibacterial and cytocompatibility properties. ${ }^{157}$ Inorganic oxides, such as $\mathrm{ZnO}$, generate surface oxygen species, leading to bacterial cell wall rupture, followed by bacterial death. ${ }^{158} \mathrm{~A}$ trace amount of $\mathrm{Zn}$ is required for many biomolecular processes, such as RNA transcription, gene expression, liquid peroxidation and maintaining an effective immune response..$^{159-161}$ In a comparative study with two cell lines (L929 and SaOS2 cell line), ZnO induced a deleterious effect to L929 cells, as revealed from an MTT assay and SEM imaging. The composite containing less than $10 \% \mathrm{ZnO}$ supported cell adhesion with filopodial and lamellipodial extensions, suggesting its cytocompatibility. There was a continuous decrease in the number of metabolically active cells, with an increase in $\mathrm{ZnO}$ content, that is mainly attributed to the toxicity of the $\mathrm{ZnO}$ particles incorporated into the HA matrix. ${ }^{157}$ An atomic absorption spectroscopic study revealed the dissolution of $11 \mathrm{and} 17 \mathrm{mg} \mathrm{l}^{-1}$ of $\mathrm{Zn}^{2+}$ ions into the culture medium, that has predominantly influenced cell death. Despite the higher antibacterial effect of $\mathrm{HA}$, with more than $20 \mathrm{wt} \% \mathrm{ZnO}$, taking into consideration the cellular response of these composites, it can be concluded that $5-7.5 \mathrm{wt} \% \mathrm{ZnO}$ addition to $\mathrm{HA}$ matrix is the optimal amount, balancing both the antibacterial and biocompatible properties to a favorable extent (Fig. 7). ${ }^{162}$ The reduction in viability of mouse fibroblast (L929) cells adhered on pure $\mathrm{HA}$ and HA-ZnO composites after 7 days, when compared to that of SaOS-2 osteoblast like cells, revealed the cell-line dependent toxicity of $\mathrm{ZnO} .{ }^{157}$ Likewise, the absorbance value obtained from the turbidimetric analysis showed a systematic decrease in the bacterial viability with an increase in $\mathrm{ZnO}$ content, irrespective of the strains used (gram positive $S$. epidermidis and gram negative E. coli) (Fig. 7b).

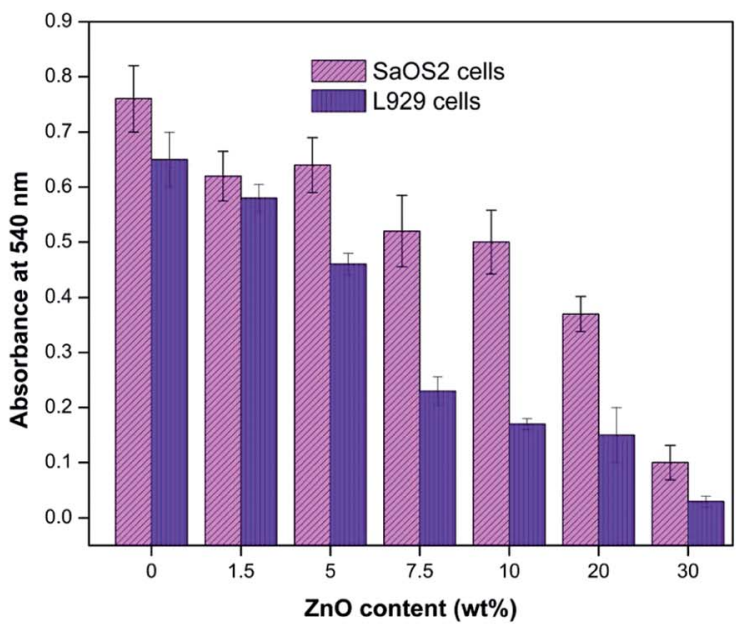

(a)

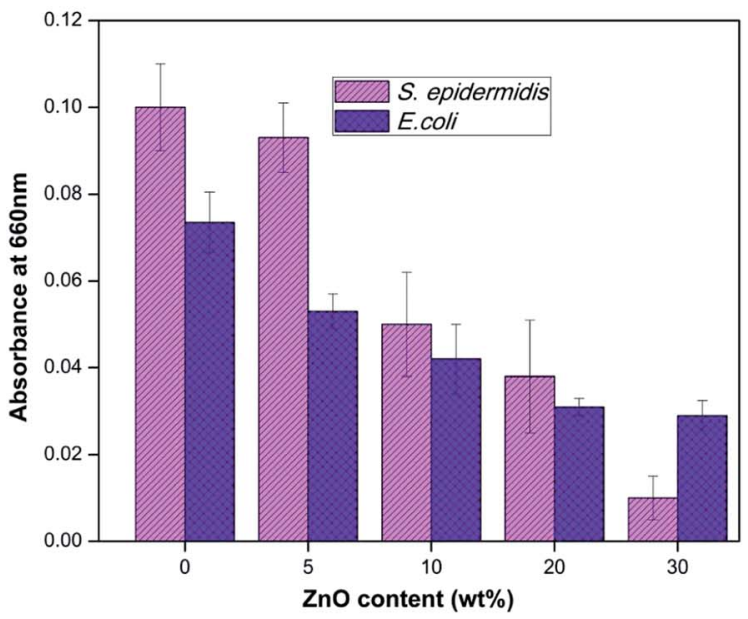

(b)

Fig. 7 (a) MTT assay results showing the viable SaOS2 osteoblast-like cells and L929 fibloblasts cells on monolithic HA and HA with varying $\mathrm{ZnO}$ content after 7 days of culture. ${ }^{67}$ (b) Mean optical density data after 4 hours of incubation with $S$. epidermidis and $E$. coli on pure $\mathrm{HA}$ and $\mathrm{HA}$ with increase in $\mathrm{ZnO}$ content. ${ }^{157,162}$ 


\subsection{HA-Ag and Ag-doped HA}

The antibacterial and disinfectant properties of silver ions and silver based compounds have been well exploited for medical purposes, from ancient times. ${ }^{\mathbf{1 6 3 , 1 6 4}}$ Due to the advent of antibiotic agents in modern medicine, the use of silver in the biomedical field has reduced drastically over the years. ${ }^{\mathbf{1 6 5}}$ Knowing its potential antimicrobial properties, several groups have started developing composites for orthopedic applications, by incorporating silver in HA to improve the antibacterial activity, ${ }^{\mathbf{1 6 6 - 1 6 9}}$ as well as the mechanical properties. ${ }^{\mathbf{1 7 0 , 1 7 1}}$ Nevertheless, one of the major concerns in reference to $\mathrm{HA}-\mathrm{Ag}$ composites is that $\mathrm{Ag}$ addition, in an amount greater than a critical value just sufficient for anti-microbial property, can reduce cell proliferation. With this basis, our group has illustrated the cytocompatibility, osteoinduction and bone mineralization (ALP and osteocalcin assay) of HA-10\% Ag composites. An important outcome of this study was that the addition of $10 \% \mathrm{Ag}$ provides a bactericidal effect against $E$. coli, without compromising the in vitro cytocompatibility of HA. Likewise, the same effect, of improved mechanical, as well as bactericidal properties was observed when 5\% silver was added to HA and CNT (carbon nanotube), to develop antibacterial composites of $\mathrm{HA}-\mathrm{Ag}$ and CNT-Ag, respectively. ${ }^{172}$ The mechanical mixing of silver with $\mathrm{HA}^{\mathbf{1 7 3}}$ occurs only at micro levels. If the ions are chemically doped to HA, then the distribution will be at the atomic level. The cytotoxicity behavior of these chemically synthesized silver doped HA samples will be different from the mechanically mixed silver with $\mathrm{HA}$. The cell adhesion and MTT assays conducted on different $\mathrm{Ca}_{10-x} \mathrm{Ag}_{2 x}\left(\mathrm{PO}_{4}\right)_{6}(\mathrm{OH})_{2}(0.0 \leq x \leq$ $0.5)$ compositions revealed that silver ion incorporation $(x \leq$ 0.2 ) in the parent phase did not hinder L929 mouse fibroblast cell spreading and growth. Importantly, the chemically doped HA showed an increase in the antimicrobial behavior, with a lower amount of silver $(x \leq 0.2)$, compared to mechanically mixed compositions. ${ }^{174}$ In brief, the method of incorporating an antimicrobial phase to a HA matrix, i.e. either physically or chemically, greatly influences its overall functional properties, especially the cellular and tissue responsse.

(A)

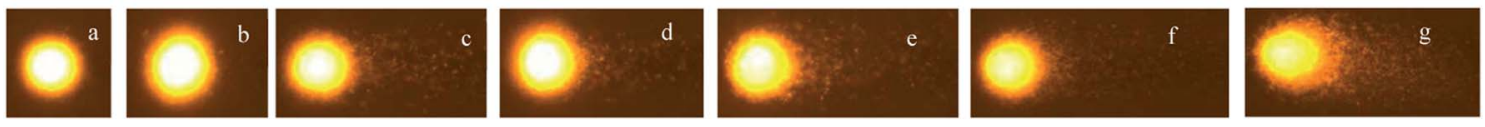

(B)
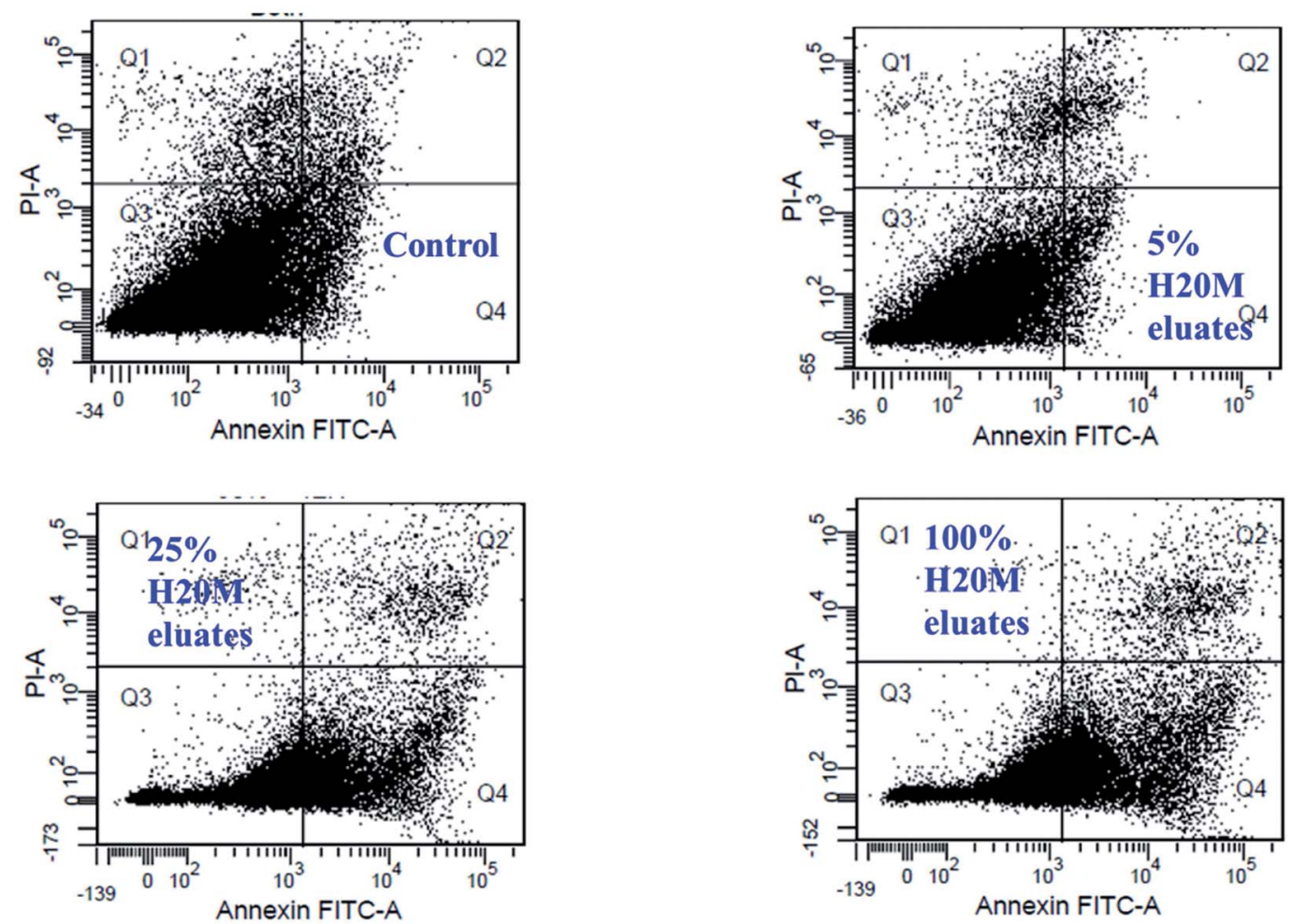

Fig. 8 (A) Representative fluorescence microscopy images revealing DNA damage of treated L929 cells after treatment with $\mathrm{H} 20 \mathrm{M}(87 \pm 12 \mathrm{~nm}$ ) nanoparticle eluate of varying eluate concentrations: (a) negative control, (b) $10 \%$, (c) $25 \%$, (d) $50 \%$, (e) $75 \%$, (f) $100 \%$ and (g) positive control. ${ }^{86}$ (B) Typical FACS dot plots illustrating the cell population distribution for hFOB cells after treating for $12 \mathrm{~h}$ with nanoparticle eluates (HA-20\% mullite composition) (Q1 - necrotic cells, Q2 - late apoptotic, Q3 - live and Q4 - early apoptotic cells). ${ }^{176,177}$ 


\subsection{HA-mullite}

In an attempt to develop a new biocomposite material with improved mechanical properties, mullite $\left(3 \mathrm{Al}_{2} \mathrm{O}_{3} \cdot 2 \mathrm{SiO}_{2}\right)$ was added as a second phase reinforcement in a HA matrix, without considerably affecting the biocompatibility. The bulk hydroxyapatite-mullite composite materials exhibited enhanced in vitro cell adhesion, cell viability and osteogenic differentiation of osteoblasts, when compared to pure HA. ${ }^{175}$ In another study by our group, L929 cells exposed to varying concentrations $(10,25$, 50,75 and $100 \%$ ) of the eluates of $\mathrm{HA}-20 \%$ mullite (HA20M), directed cellular toxicity at a dose above $50 \%$, independent of the treatment time. Based on the analysis using the comet assay, significant genotoxicity of HA20M eluates was observed, which was further related to be dependent on particle size, concentration and compostion. ${ }^{\mathbf{1 7 6}}$ In continuation, submicron to nanometer sized HA20M composite eluates were exposed to a human osteoblast cell line (hFOB 1.19) to determine the changes in the cellular behavior and gene expression in the presence of these particulate eluates. The DNA damage potential of the nanoparticle eluates has been assessed using the analysis of comets, in terms of the olive tail moment (OTM), tail length and tail DNA, as shown in Fig. 8A. Although DNA fragmentation can be observed after HA20M nanoparticle treatment to L929 cells, as shown in Fig. 8A, the extent of such damage is significantly below that observed in the case of the positive control (ethyl methanesulfonate). The results from a RT-PCR study demonstrated the concentration dependent upregulation of bone specific markers, such as cbfa, COL1 and OCN, suggesting a range of suitable concentrations with no toxicity. The apoptotic cell death studied by FACS showed increased apoptosis with an increase in the HA20M concentration and treatment time. A closer look at Fig. 8B reveals the dose dependent toxicity of a HA nanoparticulate eluate on hFOB cells. With an increasing eluate concentration, more cells enter the early/late apostosis stages. The use of FACS in this kind of quantified study is however, limited in the area of biomaterials. $^{177}$

\subsection{In vivo toxicity of $\mathrm{HA}-\mathrm{BaTiO}_{3}$ eluates}

The wear particles from a biocompatible bulk material can cause acute or chronic inflammation, which depends upon the physical properties and chemistry of the particles, as well as the immunological response of the host cells. ${ }^{178}$ Warashina et al. ${ }^{179}$ demonstrated that the ceramic particles $\left(\mathrm{Al}_{2} \mathrm{O}_{3}\right.$ and $\left.\mathrm{ZrO}_{2}\right)$ induce a reduced inflammatory response and osteolysis/bone resorption, as compared to that induced by polymeric (high-density polyethelene, HDPE) or metallic particles (Ti-6Al-4V). Among the different material types, the polymer (HDPE) was reported to cause a more intense inflammatory response. In addition, the wear particle induced apoptosis in the tissue, near to the prosthetic joint, has

Table 2 Some examples from the literature illustrating the cytocompatibility assessment of various HA based bioceramics

\begin{tabular}{|c|c|c|c|c|c|}
\hline Bioceramic composition & Cell line & $\begin{array}{l}\text { In vitro assays on } \\
\text { bulk materials }\end{array}$ & Ref. no. & Wear particulate toxicity & Ref. no. \\
\hline HA-Ti & hFOB & $\begin{array}{l}\text { MTT } \\
\text { Apoptosis assay } \\
\text { Cell cycle analysis } \\
\text { Proliferation assay }\end{array}$ & 152 & Not tested & - \\
\hline $\mathrm{HA}-\mathrm{ZnO}$ & L929, SaOS-2 & $\begin{array}{l}\text { MTT } \\
\text { SEM analysis of cell } \\
\text { Material interactions } \\
\text { Bacterial adhesion } \\
\text { and turbidimetric analysis }\end{array}$ & 157 and 162 & Not tested & - \\
\hline $\begin{array}{l}\text { HA-Ag chemically doped } \\
\text { \& mechanically mixed }\end{array}$ & L929 & $\begin{array}{l}\text { MTT } \\
\text { SEM assessment of } \\
\text { antibacterial property }\end{array}$ & $172-174$ & Not tested & - \\
\hline HA-mullite & L929, MG63 & $\begin{array}{l}\text { MTT } \\
\text { Cell adhesion } \\
\text { ALP activity } \\
\text { Osteocalcin assay }\end{array}$ & 175 & $\begin{array}{l}\text { MTT } \\
\text { SEM } \\
\text { Comet assay in L929 } \\
\text { Osteogenic gene expression } \\
\text { \& apoptosis assay in hFOB cells }\end{array}$ & 176 and 177 \\
\hline $\mathrm{HA}-\mathrm{BaTiO}_{3}$ & L929, SaOS-2 & $\begin{array}{l}\text { Fluorescence microscopy } \\
\text { MTT }\end{array}$ & 201 & $\begin{array}{l}\text { In vitro analysis (C2C12 myoblast) } \\
\text { Fluorescence microscopy } \\
\text { MTT } \\
\text { Apoptosis assay by flow cytometry } \\
\text { In vivo (BALB/c mice) } \\
\text { Histopathological examination } \\
\text { of vital organs } \\
\text { Inflammatory cytokine release } \\
\text { studies }\end{array}$ & Unpublished \\
\hline $\mathrm{HA}_{-\mathrm{CaTIO}_{3}}$ & $\mathrm{C} 2 \mathrm{C} 12$ & $\begin{array}{l}\text { MTT } \\
\text { Cell material interaction (SEM, } \\
\text { fluorescence microscopy) } \\
\text { Immunocytochemical analysis } \\
\text { of differentiation markers }\end{array}$ & 202 & Not tested & - \\
\hline
\end{tabular}


been found to be lowest in ceramics, due to their lower wear rate, whereas metallic particles induced the maximum apoptosis. ${ }^{\mathbf{1 8 0}}$

In the process of developing a bone-like piezobiocomposite, $\mathrm{BaTiO}_{3}$ was selected for its high dielectric constant and biocompatibility. Among the various $\mathrm{HA}-\mathrm{BaTiO}_{3}$ composites developed by our group, $\mathrm{HA}-40$ wt $\% \mathrm{BaTiO}_{3}$ showed mechanical and electrical properties similar to bone. Although the biocompatibility of $\mathrm{BaTiO}_{3}$ has been proved by several studies in both hard and soft tissues, ${ }^{\mathbf{1 8 1}, \mathbf{1 8 2}}$ the presence of $\mathrm{Ba}$ in the composite still raises concerns on the potential toxicity, if used as a long term implant. In view of this, $\mathrm{HA}-40 \mathrm{wt} \% \mathrm{BaTiO}_{3}$ nanoparticulates were evaluated both in vitro using myoblasts cells and in vivo, by injecting at the articular joints of mice. No trace of particle accumulation or an inflammatory response was observed upon examining the histolopathological image of the vital organs. On the contrary, particles agglomerated in the vicinity of the knee joint, with macrophages surrounding them, in an attempt to engulf and degrade the particles. Surprisingly, the particulate remained inert at the site of injection even after 7 days, instead of evoking any inflammatory cytokines.

All the above mentioned examples of cytotoxicity assessment in various bioceramic materials are summarized in Table 2.

\section{6 $\beta$-Tricalcium phosphate based bioceramics}

Another form of a calcium phosphate ceramic that show great potential in applications of bone grafts is $\beta$-tricalcium phosphate ( $\beta$-TCP). It is a well-known bioactive/partially resorbable biomaterial and has been widely studied in the past two decades, as a bone cement and tissue engineering scaffold. ${ }^{183-186}$ Due to its inadequate mechanical strength, different strategies were used in incorporating $\beta$-TCP as the biologically active phase in composites, to achieve comparable mechanical properties to natural bone. $\beta$-TCP-reinforced, high-density polyethylene composite scaffold stimulated a higher degree of proliferation, and osteogenic differentiation of the G-292 cell, which was demonstrated to be due to the high dissolution of the surfaces and high release rate of the calcium and phosphate ions into the medium. ${ }^{\mathbf{1 8 5}}$ In a similar study, an interconnected porous $\beta$-TCP scaffold infiltrated with a thin layer of poly(lactic-co-glycolic acid) (PLGA) polymer, showed a good cellular response in addition to strengthening and toughening the composite scaffolds. ${ }^{187}$ Osteoblasts cells treated even with the highest concentration of $\beta$-TCP extracts $(100 \mathrm{mg}$ $\left.\mathrm{ml}^{-1}\right)$ did not show any evidence of cytotoxicity. The $\mathrm{IC}_{50}(50 \%$ inhibitory concentration) end point assay was used to evaluate the cytotoxicity effects of the materials at different concentration applied. ${ }^{188}$ Since bone tissue comprises of multiple cell types (osteogenic cells and endothelial cells) and because of the fact that angiogenesis is a prerequisite for osteogenesis in vivo, it was demonstrated that porous interconnected $\beta$-TCP scaffolds can aid in the process of osteogenesis and angiogenesis, when human endothelial cells are co-cultured with human osteoblast cells. ${ }^{189}$

\section{Conclusions}

The recent development of novel, sophisticated, and sensitive routes to determine the toxicity and long term stability has accelerated more effective and biologically relevant testing of the biocompatibility of novel biomaterial implants. Rapid screening using in vitro cell culture models alone cannot predict the long term in vivo response, due to the reactive, degradative, kinetic and dynamic physiological environment. This obviates the necessity of evaluating different aspects, including genotoxic, epigenetic, carcinogenic and immunogenic effects, to improve the clinical acceptability of the material. Even though the safety of a newly developed material can be interpreted by comparing the biocompatibility results from both in vitro and in vivo, the exact fate of the material would be realized only after a clinical application in human patients. Therefore, a systematic toxicity evaluation at every stage of testing, through in vitro to in vivo, is essential to ensure a longer implant life.

\section{Acknowledgements}

The research results reviewed in this paper are obtained from the projects sponsored by Department of Science and Technology (DST), Department of Biotechnology (DBT) and Council for Scientific and Industrial Research (CSIR), Government of India. The authors are grateful for their financial support in the recent past. One of the authors, BB is thankful to his collaborators, including Sushma Kalmodia (currently at Shankar Nethralaya, India), Alok Kumar and Krishanu Biswas (IIT Kanpur, India), Thomas J. Webster (Northeastern University, USA), David Stout (formerly at Brown University, USA) and the toxicologists from Indian Institute for Toxicological Research, Lucknow, India (Alok Pandey, Vyom Sharma and Alok Dhawan).

\section{References}

1 B. M. Holzapfel, J. C. Reichert, J.-T. Schantz, U. Gbureck, L. Rackwitz, U. Noth, F. Jakob, M. Rudert, J. r. Groll and D. W. Hutmacher, Adv. Drug Delivery Rev., 2013, 65, 581603.

2 T. V. Thamaraiselvi and S. Rajeswari, Trends Biomater. Artif. Organs, 2004, 18, 9-17.

3 M. Vallet-Regi, J. Chem. Soc., Dalton Trans., 2001, 97.

$4 \mathrm{~W}$. Rieger, S. Leyen, S. Kobel and W. Weber, The use of bioceramics in dental and medical applications, Digital dental news, 2009, 3, 6-13.

5 L. L. Hench and J. Wilson, An Introduction to Bioceramics, World Scientific, 1993.

6 D. G. Poitout, Biomechanics and Biomaterials in Orthopedics, Springer, 2004.

7 L. L. Hench, J. Am. Ceram. Soc., 1991, 74, 1487.

8 M. Vallet-Regí, C. R. Chim., 2010, 13, 174.

9 G. P. Jayaswal, S. P. Dange and A. N. Khalikar, The Journal of Indian Prosthodontic Society, 2010, 10, 8-12.

10 D. H. Kohn, Bioceramics, Standard handbook of biomedical engineering and design, 2003.

11 C. Drouet, C. Largeot, G. Raimbeaux, C. Estournès, G. Dechambre, C. Combes and C. Rey, Adv. Sci. Technol., 2006, 49, 45-50.

12 Y. W. Gu, N. H. Loh, K. A. Khor, S. B. Tor and P. Cheang, Biomaterials, 2002, 23, 37. 
13 T. Murakami, A. Kitahara, Y. Koga, M. Kawahara, H. Inui and M. Yamaguchi, Mater. Sci. Eng., A, 1997, 239-240, 672-679.

14 B. Ben-Nissan and G. Pezzotti, J. Ceram. Soc. Jpn., 2002, 110, 601.

15 A. Abarrategi, C. Moreno-Vicente, F. J. MartÃnez-VÃ $i z q u e z$, A. Civantos, V. Ramos, J. V. Sanz-Casado, et al., PLoS One, 2012, 7, e34117.

16 S. M. Best, A. E. Porter, E. S. Thian and J. Huang, J. Eur. Ceram. Soc., 2008, 28, 1319.

17 J. Heil, G. Reifferscheid, P. Waldmann, G. Leyhausen and W. Geurtsen, Mutat. Res., Genet. Toxicol., 1996, 368, 181194.

18 P. E. Murray, C. Garcia-Godoy and F. Garcia-Godoy, Med. Oral Patol. Oral Cir. Bucal, 2007, 12, E258-E266.

19 R. Quan, Y. Tang, Z. Huang, J. Xu, X. Wu and D. Yang, Mater. Sci. Eng., C, 2013, 33(3), 1332-1338.

20 J. M. Anderson, Annu. Rev. Mater. Res., 2001, 31, 81.

21 C. J. Kirkpatrick, F. Bittinger, M. Wagner, H. Kahler, T. G. van Kooten, C. L. Klein and M. Otto, Proc. Inst. Mech. Eng., Part H, 1998, 212, 75.

22 J. C. Wataha, J. Prosthet. Dent., 2001, 86, 203.

23 K. B. Hellman, G. L. Picciolo and C. F. Fox, J. Cell. Biochem., 1994, 56, 210.

24 M. N. Helmus, D. F. Gibbons and D. Cebon, Toxicol. Pathol., 2008, 36, 70-80.

25 W. Elshahawy, Advances in Ceramics - Electric and Magnetic Ceramics, Bioceramics, Ceramics and Environment, Intech, 2011.

26 N. R. Patel and P. P. Gohil, Int. J. Emerg. Technol. Adv. Eng., 2012, 2, 91-101.

27 C. M. Agrawal, JOM, 1998, 50, 31.

28 A. Rosengren, L. Faxius, N. Tanaka, M. Watanabe and L. M. Bjursten, J. Biomed. Mater. Res., Part A, 2005, 75, 115-122.

29 B. Fadeel and A. E. Garcia-Bennett, Adv. Drug Delivery Rev., 2010, 62, 362-374.

30 A. Pizzoferrato, G. Ciapetti, S. Stea, E. Cenni, C. R. Arciola, D. Granchi and L. Savarino, Clin. Mater., 1994, 15(3), 173190.

31 M. O. Wang, J. M. Etheridge, J. A. Thompson, C. E. Vorwald, D. Dean and J. P. Fisher, Biomacromolecules, 2013, 14, 13211329.

32 A. P. Wieslander, M. K. Nordin, B. Hansson, B. Baldetorp and P. T. Kjellstrand, Biomater., Artif. Cells, Immobilization Biotechnol., 1993, 21, 63-70.

33 E. A. Van Tienhoven, D. Korbee, L. Schipper, H. W. Verharen and W. H. De Jong, J. Biomed. Mater. Res., Part A, 2006, 78, 175-182.

34 J. C. Park, B. J. Park, D. H. Lee, H. Suh, D. G. Kim and O. H. Kwon, Yonsei Med. J., 2002, 43, 518-526.

35 S. Jain, A. Sharma and B. Basu, J. Biomed. Mater. Res., Part B, 2013, 101, 520-531.

36 G. Tripathi and B. Basu, Ceram. Int., 2012, 38, 341.

37 M. A. F. Afzal, P. Kesarwani, K. M. Reddy, S. Kalmodia, B. Basu and K. Balani, Mater. Sci. Eng., C, 2012, 32, 11641173.
38 J. R. Wilson, J. G. Mills, I. D. Prather and S. D. Dimitrijevich, Adv. Skin Wound Care, 2005, 18, 373-378.

39 A. Kroll, C. Dierker, C. Rommel, D. Hahn, W. Wohlleben, C. Schulze-Isfort, C. Gobbert, M. Voetz, F. Hardinghaus and J. Schnekenburger, Part. Fibre Toxicol., 2011, 23(8), 9.

40 G. Ciapetti, E. Cenni, L. Pratelli and A. Pizzoferrato, Biomaterials, 1993, 14, 359.

41 S. Dinescu, B. Galateanu, M. Albu, A. Lungu, E. Radu, A. Hermenean and M. Costache, BioMed Res. Int., 2013, DOI: $10.1155 / 2013 / 598056$.

42 S. Neuss, C. Apel, P. Buttler, B. Denecke, A. Dhanasingh, X. Ding, D. Grafahrend, A. Groger, K. Hemmrich, A. Herr, W. Jahnen-Dechent, S. Mastitskaya, A. Perez-Bouza, S. Rosewick, J. Salber, M. Woltje and M. Zenke, Biomaterials, 2008, 29, 302.

43 C. T. Hanks, J. C. Wataha and Z. Sun, Dent. Mater., 1996, 12, 186-193.

44 B. D. Boyan, V. L. Sylvia, Y. Liu, R. Sagun, D. L. Cochran, C. H. Lohmann, et al., Biomaterials, 1999, 20, 2305-2310.

45 M. Rasekh, Z. Ahmad, C. C. Frangos, L. Bozec, M. Edirisinghe and R. M. Day, Acta Biomater., 2013, 9, 5052.

46 J. Folkman and A. Moscona, Nature, 1978, 273, 345-349.

47 Y. Song, Y. Ju, G. Song and Y. Morita, Int. J. Nanomed., 2013, 8, 2745-2756.

48 M. Vielreicher, S. Schurmann, R. Detsch, M. A. Schmidt, A. Buttgereit, A. Boccaccini and O. Friedrich, J. R. Soc. Interface, 2013, 10, 20130263.

49 L. Tayebi, A. Nozari, D. Vashaee and M. Mozafari, Current Microscopy Contributions to Advances in Science and Technology, 2012.

50 X. Liu, M. Zhao, J. Lu, J. Ma, J. Wei and S. Wei, Int. J. Nanomed., 2012, 7, 1239.

$51 \mathrm{~J}$. Vilches and J. I. Vilches-Perez, Modern Research and Educational Topics in Microscopy, 2007.

52 E. Filova, Z. Burdikova, M. Rampichova, P. Bianchini, M. Capek, E. Kostakova, E. Amler and L. Kubinova, J. Biomed. Opt., 2010, 15, 066011.

53 B. Kinikoglu, C. Auxenfans, P. Pierrillas, V. Justin, P. Breton, C. Burillon, V. Hasirci and O. Damour, Biomaterials, 2009, 30, 6418.

54 T. Matsuda and S. Nagahara, ASAIO J., 1995, 41(3), M398M403.

55 Y. C. Wang, S. H. Kao and H. J. Hsieh, Biomacromolecules, 2003, 4, 224-231.

56 R. Narayan, T. Boland and Y. S. Lee, Printed Biomaterials: Novel Processing and Modeling Techniques for Medicine and Surgery, Springer, 2009.

57 S. Kato, T. Akagi, K. Sugimura, A. Kishida and M. Akashi, Biomaterials, 1998, 19, 821-827.

58 W. G. Brodbeck, G. Voskerician, N. P. Ziats, Y. Nakayama, T. Matsuda and J. M. Anderson, J. Biomed. Mater. Res., 2003, 64, 320-329.

59 A. Rodriguez, H. Meyerson and J. M. Anderson, J. Biomed. Mater. Res., Part A., 2009, 89A, 152-159.

60 A. Hatton, J. E. Nevelos, A. A. Nevelos, R. E. Banks, J. Fisher and E. Ingham, Biomaterials, 2002, 23, 3429. 
61 S. Lerouge, O. Huk, L. Yahia, J. Witvoet and L. Sedel, J. Bone Jt. Surg., Br. Vol., 1997, 79, 135-139.

62 E. J. Henssge, I. Bos and G. Willmann, J. Mater. Sci.: Mater. Med., 1994, 5, 657.

63 E. Ingham and J. Fisher, Proc. Inst. Mech. Eng., Part H, 2000, 214, 21.

64 Q. Saquib, A. A. Al-Khedhairy, M. A. Siddiqui, F. M. AbouTarboush, A. Azam and J. Musarrat, Toxicol. in Vitro, 2012, 26, 351-361.

65 E.-J. Park, J. Yi, K.-H. Chung, D.-Y. Ryu, J. Choi and K. Park, Toxicol. Lett., 2008, 180, 222-229.

66 M. Ahamed, H. A. Alhadlaq, J. Alam, M. A. Khan, D. Ali and S. Alarafi, Curr. Pharm. Des., 2013, 19, 6681-6690.

67 C. Genies, A. Maître, E. Lefèbvre, A. Jullien, M. ChopardLallier, et al., PLoS One, 2013, 8, e78356.

68 M. Christmann and B. Kaina, Nucleic Acids Res., 2013, 41, 8403-8420.

69 L. Xu, X. Li, T. Takemura, N. Hanagata, G. Wu and L. L. Chou, J. Nanobiotechnol., 2012, 10, 16.

70 X. Liu and J. Sun, Biomaterials, 2010, 31, 8198.

71 B. N. Ames, W. E. Durstan, E. Yamasaki and F. D. Lee, Proc. Natl Acad. Sci. USA, 1975, 70, 2281-2285.

72 E. F. DiCarlo and P. G. Bullough, Clin. Mater., 1992, 9, 235.

73 K. Takamura, K. Hayashi, N. Ishinishi, T. Yamada and Y. Sugioka, J. Biomed. Mater. Res., 1994, 28, 583.

74 A. Martin, T. W. Bauer, M. T. Manley and K. E. Marks, J. Bone Joint Surg. Am., 1988, 70, 1561-1567.

75 D. B. McGregor, R. A. Baan, C. Partensky, J. M. Rice and J. D. Wilbourn, Eur. J. Cancer, 2000, 36, 307.

76 N. Fabbri, E. Rustemi, C. Masetti, J. Kreshak, M. Gambarotti, D. Vanel, A. Toni and M. Mercuri, Eur. J. Radiol., 2011, 77, 43.

77 G. Maccauro, P. Rossi Iommetti, L. Raffaelli and P. F. Manicone, Biomaterials Applications for Nanomedicine, InTech, 2011.

78 P. Griss, E. Werner, R. Buchinger, C. M. Busing and G. Heimke, Arch. Orthop. Unfall-Chir., 1977, 90(1), 29-40.

79 D. L. Wise, D. J. Trantolo, K.-U. Lewandrowski, J. D. Gresser, M. V. Cattaneo and M. J. Yaszemski, Biomaterials Engineering and Devices: Human Applications, Orthopedic, Dental, and Bone Graft Applications, 2000, vol. 2.

80 V. V. Skorokhod, S. M. Solonin, V. A. Dubok, L. L. Kolomiets, T. V. Permyakova and A. V. Shinkaruk, Powder Metall. Met. Ceram., 2010, 49, 324-329.

81 M. Topaktas, E. S. Istifli, M. Buyukleyla, H. B. Ila, T. Canitezer and M. Kurkcu, Turk. J. Biol., 2012, 36, 568573.

82 Y. Yuan, C. Liu, J. Qian, J. Wang and Y. Zhang, Biomaterials, 2010, 31(4), 730-740.

83 X. Zhao, S. Ng, B. C. Heng, J. Guo, L. Ma, T. T. Tan, K. W. Ng and S. C. Loo, Arch. Toxicol., 2012, 87(6), 1037-1052.

84 Z. Xu, C. Liu, J. Wei and J. Sun, J. Appl. Toxicol., 2012, 32, $429-435$.

85 J. Hu, Z. S. Liu, S. L. Tang and Y. M. He, World J. Gastroenterol., 2007, 13, 2798-2802.

86 J. Sun and T. Ding, J. Biomed. Mater. Res., Part A, 2009, 88, 673-679.
87 S. Macip, M. Igarashi, P. Berggren, J. Yu, S. W. Lee and S. A. Aaronson, Mol. Cell. Biol., 2003, 23, 8576-8585.

88 C. Jun, C. Xianying, L. Shipu, H. Yingchao and Z. Ran, J. Wuhan Univ. Technol., Mater. Sci. Ed., 2005, 20, 57-59.

89 T. P. Kannan, B. B. Quah, A. Azlina and A. R. Samsudin, Arch. Orofac. Sci., 2006, 1, 15-20.

90 S. H. Teoh, Int. J. Fatigue, 2000, 22, 825.

91 H. S. A. Rahman, D. Choudhury, N. A. A. Osman, H. N. Shasmin and W. A. B. W. Abas, J. Ceram. Soc. Jpn., 2013, 121, 382-387.

92 S. Wakayama, Y. Suzuki, T. Oshima and S. Kobayashi, JSME Int. J., Ser. A, 2006, 49(1), 11-14.

93 J. Vivanco, A. Aiyangar, A. Araneda and H.-L. Ploeg, J. Mech. Behav. Biomed. Mater., 2012, 9, 137.

94 S. Suner, J. L. Tipper and N. Emami, Tribol.-Mater., Surf. Interfaces, 2012, 6, 39.

95 F. Benazzo, F. Falez, M. Dietrich, S. Affatato, W. Leardini and M. Zavalloni, Bioceramics and Alternative Bearings in Joint Arthroplasty, Steinkopff, 2006, p. 171.

96 J. Nevelos, E. Ingham, C. Doyle, R. Streicher, A. Nevelos, W. Walter and J. Fisher, J. Arthroplasty, 2000, 15, 793-795.

97 J. L. Tipper, A. Hatton, J. E. Nevelos, E. Ingham, C. Doyle, R. Streicher, A. B. Nevelos and J. Fisher, Biomaterials, 2002, 23, 3441-3448.

98 A. I. Pearce, R. G. Richards, S. Milz, E. Schneider and S. G. Pearce, Eur. Cells Mater., 2007, 2, 1-10.

99 C. Schouten, G. J. Meijer, J. J. van den Beucken, P. H. Spauwen and J. A. Jansen, Clin. Oral Implants Res., 2010, 21, 414-423.

100 M. Egermann, J. Goldhahn and E. Schneider, Osteoporosis Int., 2005, 16(Suppl 2), S129-S138.

101 R. Albulescu, E. Codorean, L. Albulescu, G. Caraene, V. Vulturescu and C. Tanase, Rom. Biotechnol. Lett., 2008, 13, 3863-3872.

102 J. E. Davies and N. Baldan, J. Biomed. Mater. Res., 1997, 36, 429-440.

103 M. del Cerro, J. Cogen and C. del Cerro, Microsc. Acta, 1980, 83, 117-121.

104 P. Prento, Histochemistry, 1993, 99, 163-174.

105 G. Tripathi, J. E. Gough, A. Dinda and B. Basu, J. Biomed. Mater. Res., Part A, 2013, 101, 1539-1549.

106 A. Piattelli, P. Trisi and M. Emanuelli, Int. J. Oral Maxillofac. Implants, 1993, 8, 69-74.

107 M. Neo, S. Kotani, Y. Fujita, T. Nakamura, T. Yamamuro, Y. Bando, C. Ohtsuki and T. Kokubo, J. Biomed. Mater. Res., 1992, 26, 255-267.

108 C. K. Chang, J. S. Wu, D. L. Mao and C. X. Ding, J. Biomed. Mater. Res., 2001, 56, 17-23.

109 K. Yamaki, Y. Kataoka, F. Ohtsuka and T. Miyazaki, Dent. Mater. J., 2012, 31, 427-432.

110 P. O. Ostman, On Various Protocols for Direct Loading of Implant-Supported Fixed Prostheses, Department of Biomaterials, Institute of Clinical Sciences, Sahlgrenska Academy, Goteborg University, 2007.

111 S. S. Pikner, Swed. Dent. J. Suppl., 2008, 194, 5-69, 2.

112 A. Palmquist, On a Novel Technique for Preparation and Analysis of the Implant Surface and Its Interface to Bone, 
Department of Biomaterials, Institute of Clinical Sciences, Sahlgrenska Academy at University of Gothenburg, 2008.

113 Y. Numata, T. Sakae, H. Nakada, T. Suwa, R. Z. LeGeros, Y. Okazaki and K. Kobayashi, Journal of Hard Tissue Biology, 2007, 16, 91-93.

114 N. Stoppie, J. P. van der Waerden, J. A. Jansen, J. Duyck, M. Wevers and I. E. Naert, Clin. Implant Dent. Relat. Res., 2005, 7, 87-94.

115 R. Cancedda, A. Cedola, A. Giuliani, V. Komlev, S. Lagomarsino, M. Mastrogiacomo, F. Peyrin and F. Rustichelli, Biomaterials, 2007, 28, 2505-2524.

116 F. Benazzo, F. Falez, M. Dietrich, S. Affatato, W. Leardini and M. Zavalloni, in Bioceramics and Alternative Bearings in Joint Arthroplasty, Steinkopff, 2006, vol. 171.

117 J. Olofsson, Friction and Wear Mechanisms of Ceramic Surfaces: With Applications to Micro Motors and Hip Joint Replacements, Digital Comprehensive Summaries of Uppsala Dissertations from the Faculty of Science and Technology, Acta Universitatis Upsaliensis, Uppsala, 2011, p. 841.

118 J. E. Nevelos, E. Ingham, C. Doyle, A. B. Nevelos and J. Fisher, J. Mater. Sci.: Mater. Med., 2001, 12, 141.

119 G. E. Totten and H. Liang, Mechanical Tribology: Materials, Characterization, and Applications, Taylor \& Francis, 2004.

120 D. C. Hansen, Electrochem. Soc. Interface, 2008, 17(2), 31-34. 121 C. Kasper, F. Witte, R. Portner, D. Das, Z. Zhang, T. Winkler, M. Mour, C. Gunter, M. Morlock, H.-G. Machens and A. Schilling, in Tissue Engineering III: Cell - Surface Interactions for Tissue Culture, Springer Berlin Heidelberg, 2012, vol. 126, p. 317.

122 H. J. Fruh, G. Willmann and H. G. Pfaff, Biomaterials, 1997, 18, 873 .

123 G. Willmann, H. J. Fruh and H. G. Pfaff, Biomaterials, 1996, 17, 2157.

124 I. Catelas, A. Petit, R. Marchand, D. J. Zukor, L. Yahia and O. L. Huk, J. Bone Jt. Surg., Br. Vol., 1999, 81(3), 516-521.

125 A. Hatton, J. E. Nevelos, J. B. Matthews, J. Fisher and E. Ingham, Biomaterials, 2003, 24, 1193.

126 L. Imbert, Working principle of the dual mobility (total hip replacement): wear mechanisms and design optimization, Chalmers University of Technology, Göteborg, 2011.

127 A. Katzer, S. Hockertz, G. H. Buchhorn and J. F. Loehr, Toxicology, 2003, 190, 145-154.

128 J. M. Dorlot, P. Christel and A. Meunier, J. Biomed. Mater. Res., 1989, 23, 299-310.

129 B. Liagre, S. Moalic, P. Vergne, J. L. Charissoux, D. Bernache-Assollant and J. L. Beneytout, J. Bone Jt. Surg., Br. Vol., 2002, 84, 920-930.

130 J. Li, Y. Liu, L. Hermansson and R. Soremark, Clin.Mater., 1993, 12, 197-201.

131 P. Laquerriere, L. Kilian, A. Bouchot, E. Jallot, A. Grandjean, M. Guenounou, G. Balossier, P. Frayssinet and P. Bonhomme, J. Biomed. Mater. Res., 2001, 58, 238-246.

132 S. Orrenius, P. Nicotera and B. Zhivotovsky, Toxicol. Sci., 2010, 119, 3.

133 R. Iyer, R. F. Hamilton, L. Li and A. Holian, Toxicol. Appl. Pharmacol., 1996, 141, 84-92.
134 Z. Darzynkiewicz, S. Bruno, G. Del Bino, W. Gorczyca, M. A. Hotz, P. Lassota and F. Traganos, Cytometry, 1992, 13, 795-808.

135 Y. Gavrieli, Y. Sherman and S. A. Ben-Sasson, J. Cell Biol., 1992, 119, 493-501.

136 A. Saraste, Herz/Kreislauf, 1999, 24, 189-195.

137 V. Wilhelmi, U. Fischer, D. van Berlo, K. Schulze-Osthoff, R. P. Schins and C. Albrecht, Toxicol. in Vitro, 2012, 26, 323-334.

138 M. A. Siddiqui, H. A. Alhadlaq, J. Ahmad, A. A. AlKhedhairy, J. Musarrat and M. Ahamed, PLoS One, 2013, 8, e69534.

139 J. Zhao, L. Bowman, X. Zhang, V. Vallyathan, S. H. Young, V. Castranova and M. Ding, J. Toxicol. Environ. Health, Part A, 2009, 72, 1141-1149.

140 J. R. Lepock, H. E. Frey, A. M. Rodahl and J. Kruuv, J. Cell. Physiol., 1988, 137, 14-24.

141 A. Doostmohammadi, A. Monshi, M. H. Fathi, S. Karbasi, O. Braissant and A. U. Daniels, J. Mater. Sci.: Mater. Med., 2011, 22, 2293-2300.

142 M. Tavakoli, E. Bateni, M. Rismanchian, M. Fathi, A. Doostmohammadi, A. Rabiei, H. Sadeghi, M. Etebari and M. Mirian, Dent. Res. J. (Isfahan), 2012, 9, 314-320.

143 S. Jantova, M. Theiszova, S. Letasiova, L. Birosova and T. M. Palou, Mutat. Res., Genet. Toxicol. Environ. Mutagen., 2008, 652, 139-144.

144 M. Theiszova, S. Jantova, S. Letasiova, M. Palou and L. Cipak, Neoplasma, 2008, 55, 312-316.

145 R. Quan, Y. Tang, Z. Huang, J. Xu, X. Wu and D. Yang, Mater. Sci. Eng., C, 2013, 33, 1332-1338.

$146 \mathrm{~J}$. Black, Orthopaedic biomaterials in research and practice, Churchill Livingstone, 1988.

147 H. Dasarathy, C. Riley, H. D. Coble, W. R. Lacefield and G. Maybee, J. Biomed. Mater. Res., 1996, 31, 81-89.

148 C. Q. Ning and Y. Zhou, Biomaterials, 2004, 25, 3379-3387. 149 Y. J. Han, S. C. Loo, J. Lee and J. Ma, BioFactors, 2007, 30, 205-216.

150 J. L. Ong, M. Appleford, S. Oh, Y. Yang, W. H. Chen, J. D. Bumgardner and W. O. Haggard, JOM, 2006, 58, 67.

151 R. Noort, J. Mater. Sci., 1987, 22, 3801-3811.

152 A. Kumar, T. J. Webster, K. Biswas and B. Basu, J. Biomed. Mater. Res., Part A., 2013, 101, 2925-2938.

153 B. O. Palsson and S. N. Bhatia, Tissue Engineering, Pearson Education, 2009.

154 Y. Yang and J. L. Ong, J. Biomed. Mater. Res., 2003, 64, 509516.

155 P. Berube, Y. Yang, D. L. Carnes, R. E. Stover, E. J. Boland and J. L. Ong, J. Periodontol., 2005, 76, 1697-1709.

156 B. M. Chesnutt, Y. Yuan, N. Brahmandam, Y. Yang, J. L. Ong, W. O. Haggard and J. D. Bumgardner, J. Biomed. Mater. Res., Part A, 2007, 82, 343.

157 N. Saha, A. K. Dubey and B. Basu, J. Biomed. Mater. Res., Part $B, 2012,100,256-264$.

158 N. Padmavathy and R. Vijayaraghavan, Sci. Technol. Adv. Mater., 2008, 9, 035004.

159 A. Ito, K. Ojima, H. Naito, N. Ichinose and T. Tateishi, J. Biomed. Mater. Res., 2000, 50, 178-183. 
160 H. Tapiero and K. D. Tew, Biomed. Pharmacother., 2003, 57, 399-411.

161 E. Mocchegiani, M. Muzzioli and R. Giacconi, Trends Pharmacol. Sci., 2000, 21, 205-208.

162 N. Saha, K. Keskinbora, E. Suvaci and B. Basu, J. Biomed. Mater. Res., Part B, 2010, 95, 430-440.

163 V. Alt, T. Bechert, P. Steinrucke, M. Wagener, P. Seidel, E. Dingeldein, E. Domann and R. Schnettler, Biomaterials, 2004, 25, 4383-91.

164 J. S. Kim, E. Kuk, K. N. Yu, J. H. Kim, S. J. Park, H. J. Lee, et al., Nanomed.: Nanotechnol., Biol. Med., 2007, 3, 95-101.

165 X. Chen and H. J. Schluesener, Toxicol. Lett., 2008, 176, 112.

166 W. Chen, Y. Liu, H. S. Courtney, M. Bettenga, C. M. Agrawal, J. D. Bumgardner and J. L. Ong, Biomaterials, 2006, 27, 5512-5517.

167 W. Chen, S. Oh, A. P. Ong, N. Oh, Y. Liu, H. S. Courtney, M. Appleford and J. L. Ong, J. Biomed. Mater. Res., Part A, 2007, 82, 899-906.

168 M. Roy, G. A. Fielding, H. Beyenal, A. Bandyopadhyay and S. Bose, ACS Appl. Mater. Interfaces, 2012, 4, 1341-1349.

169 G. A. Fielding, M. Roy, A. Bandyopadhyay, S. Bose and A. Biomater, 2012, 8, 3144-3152.

170 X. Zhang, G. H. M. Gubbels, R. A. Terpstra and R. Metselaar, J. Mater. Sci., 1997, 32, 235-243.

171 B.-T. Lee, N.-Y. Shin, J.-K. Han and H.-Y. Song, Mater. Sci. Eng., A, 2006, 429, 348-352.

172 M. A. Afzal, S. Kalmodia, P. Kesarwani, B. Basu and K. Balani, J. Biomater. Appl., 2012, 27, 967-978.

173 S. Nath, S. Kalmodia and B. Basu, J. Mater. Sci.: Mater. Med., 2010, 21, 1273-1287.

174 B. Singh, A. K. Dubey, S. Kumar, N. Saha, B. Basu and R. Gupta, Mater. Sci. Eng., C, 2011, 31, 1320-1329.

175 S. Nath, S. Kalmodia and B. Basu, J. Biomater. Appl., 2013, 27, 497-509.

176 S. Kalmodia, V. Sharma, A. K. Pandey, A. Dhawan and B. Basu, J. Biomed. Nanotechnol., 2011, 7, 74-75.

177 S. Kalmodia, B. Basu and T. J. Webster, J. Biomater. Appl., 2013, 27, 891-908.

178 P. A. Revell, The biological effects of nanoparticles, Nanotechnol. Perceptions, 2006, 2, 283-298.

179 H. Warashina, S. Sakano, S. Kitamura, K.-I. Yamauchi, J. Yamaguchi, N. Ishiguro and Y. Hasegawa, Biomaterials, 2003, 24, 3655-3661.

180 S. Stea, M. Visentin, D. Granchi, E. Cenni, G. Ciapetti, A. Sudanese and A. Toni, Biomaterials, 2000, 21, 1393-1398.

181 J. B. Park, G. H. Kenner, S. D. Brown and J. K. Scott, Biomater., Med. Devices, Artif. Organs, 1977, 5, 267-276.
182 J. B. Park, A. F. von Recum, G. H. Kenner, B. J. Kelly, W. W. Coffeen and M. F. Grether, J. Biomed. Mater. Res., 1980, 14, 269-277.

183 S. Ni, J. Chang, L. Chou and W. Zhai, J. Biomed. Mater. Res., Part B, 2007, 80(1), 174-183.

184 Y. Kang, S. Kim, A. Khademhosseini and Y. Yang, Biomaterials, 2011, 32, 6119-6130.

185 S. Homaeigohar, M. A. Shokrgozar, A. Y. Sadi, A. Khavandi, J. Javadpour and M. Hosseinalipour, J. Biomed. Mater. Res., Part A, 2005, 75, 14-22.

186 M. Kamitakahara, C. Ohtsuki and T. Miyazaki, J. Biomater. Appl., 2008, 23(3), 197-212, DOI: 10.1177/ 0885328208096798.

187 Y. Kang, A. Scully, D. A. Young, S. Kim, H. Tsao, M. Sen and Y. Yang, Eur. Polym. J., 2011, 47(8), 1569-1577.

188 N. M. Naziri, D. Mohamadi, M. D. A. S. Mohamed, N. S. Omari and R. Othman, J. Eng. Sci. Technol., 2012, 7, 169-176.

189 Y. Kang, S. Kim, M. Fahrenholtz, A. Khademhosseini and Y. Yang, Acta Biomater., 2013, 9, 4906-4915.

190 M. C. Elia, R. D. Storer, L. S. Harmon, A. R. Kraynak, T. W. McKelvey, P. R. Hertzog, K. P. Keenan, J. G. DeLuca and W. W. Nichols, Mutat. Res., Environ. Mutagen. Relat. Subj., 1993, 291, 193-205.

191 T. Mosmann, J. Immunol. Methods, 1983, 65, 55-63.

192 A. H. Cory, T. C. Owen, J. A. Barltrop and J. G. Cory, Cancer Commun., 1991, 3, 207-212.

193 G. Malich, B. Markovic and C. Winder, Toxicology, 1997, 124, 179-192.

194 M. G. Stevens and S. C. Olsen, J. Immunol. Methods, 1993, 157, 225-231.

195 M. Ishiyama, Y. Miyazono, K. Sasamoto, Y. Ohkura and K. Ueno, Talanta, 1997, 44, 1299-1305.

196 R. K. Shukla, V. Sharma, A. K. Pandey, S. Singh, S. Sultana and A. Dhawan, Toxicol. in Vitro, 2011, 25, 231-241.

197 V. Sharma, R. K. Shukla, N. Saxena, D. Parmar, M. Das and A. Dhawan, Toxicol. Lett., 2009, 185, 211-218.

198 J. O'Brien, I. Wilson, T. Orton and F. Pognan, Eur. J. Biochem., 2000, 267, 5421-5426.

199 R. D. Fields and M. V. Lancaster, Am. Biotechnol. Lab., 1993, 11, 48-50.

200 E. M. Larson, D. J. Doughman, D. S. Gregerson and W. F. Obritsch, Invest. Ophthalmol. Visual Sci., 1997, 38, 1929-1933.

201 A. K. Dubey, P. Agrawal, R. D. Misra and B. Basu, J. Mater. Sci.: Mater. Med., 2013, 24, 1789.

202 G. Thrivikraman, P. K. Mallik and B. Basu, Biomaterials, 2013, 34, 7073. 